\title{
Recent Advances of Hyperspectral Imaging Technology and Applications in Agriculture
}

\author{
Bing Lu ${ }^{1}$, Phuong D. Dao ${ }^{1,2} \oplus$, Jiangui Liu ${ }^{3}$, Yuhong $\mathrm{He}^{1, *}$ and Jiali Shang ${ }^{3}$ \\ 1 Department of Geography, Geomatics and Environment, University of Toronto Mississauga, \\ 3359 Mississauga Road, Mississauga, ON L5L 1C6, Canada; bing.lu@mail.utoronto.ca (B.L.); \\ phuong.dao@mail.utoronto.ca (P.D.D.) \\ 2 School of the Environment, University of Toronto, 33 Willcocks Street, Toronto, ON M5S 3E8, Canada \\ 3 Agriculture and Agri-Food Canada, 960 Carling Avenue, Ottawa, ON K1A 0C6, Canada; \\ jiangui.liu@canada.ca (J.L.); jiali.shang@Canada.ca (J.S.) \\ * Correspondence: yuhong.he@utoronto.ca
}

Received: 12 July 2020; Accepted: 16 August 2020; Published: 18 August 2020

check for updates

\begin{abstract}
Remote sensing is a useful tool for monitoring spatio-temporal variations of crop morphological and physiological status and supporting practices in precision farming. In comparison with multispectral imaging, hyperspectral imaging is a more advanced technique that is capable of acquiring a detailed spectral response of target features. Due to limited accessibility outside of the scientific community, hyperspectral images have not been widely used in precision agriculture. In recent years, different mini-sized and low-cost airborne hyperspectral sensors (e.g., Headwall Micro-Hyperspec, Cubert UHD 185-Firefly) have been developed, and advanced spaceborne hyperspectral sensors have also been or will be launched (e.g., PRISMA, DESIS, EnMAP, HyspIRI). Hyperspectral imaging is becoming more widely available to agricultural applications. Meanwhile, the acquisition, processing, and analysis of hyperspectral imagery still remain a challenging research topic (e.g., large data volume, high data dimensionality, and complex information analysis). It is hence beneficial to conduct a thorough and in-depth review of the hyperspectral imaging technology (e.g., different platforms and sensors), methods available for processing and analyzing hyperspectral information, and recent advances of hyperspectral imaging in agricultural applications. Publications over the past 30 years in hyperspectral imaging technology and applications in agriculture were thus reviewed. The imaging platforms and sensors, together with analytic methods used in the literature, were discussed. Performances of hyperspectral imaging for different applications (e.g., crop biophysical and biochemical properties' mapping, soil characteristics, and crop classification) were also evaluated. This review is intended to assist agricultural researchers and practitioners to better understand the strengths and limitations of hyperspectral imaging to agricultural applications and promote the adoption of this valuable technology. Recommendations for future hyperspectral imaging research for precision agriculture are also presented.
\end{abstract}

Keywords: precision agriculture; remote sensing; hyperspectral imaging; platforms and sensors; analytical methods; crop properties; soil characteristics; classification of agricultural features

\section{Introduction}

The global agricultural sector is facing increasing challenges posed by a range of stressors, including a rapidly growing population, the depletion of natural resources, environmental pollution, crop diseases, and climate change. Precision agriculture is a promising approach to address these challenges through improving farming practices, e.g., adaptive inputs (e.g., water and fertilizer), ensured outputs (e.g., crop yield and biomass), and reduced environmental impacts. Remote sensing 
is capable of identifying within-field variability of soils and crops and providing useful information for site-specific management practices [1,2]. There are two types of remote sensing technologies given the source of energy, passive (e.g., optical) and active remote sensing (e.g., LiDAR and Radar). Passive optical remote sensing is usually further divided into two groups based on the spectral resolutions of sensors, multispectral and hyperspectral remote sensing [3]. Multispectral imaging is facilitated by collecting spectral signals in a few discrete bands, each spanning a broad spectral range from tens to hundreds of nanometers. In contrast, hyperspectral imaging detects spectral signals in a series of continuous channels with a narrow spectral bandwidth (e.g., typically below $10 \mathrm{~nm}$ ); therefore, it can capture fine-scale spectral features of targets that otherwise could be compromised [4].

Multispectral images (e.g., Landsat, Sentinel 2, and SPOT images) have been widely used in agricultural studies to retrieve various crop and soil attributes, such as crop chlorophyll content, biomass, yield, and soil degradation [5-10]. However, due to the limitations in spectral resolution, the accuracy of the retrieved variables is often limited, and early signals of crop stresses (e.g., nutrient deficiency, crop disease) cannot be effectively detected in a timely manner [11]. Hyperspectral images (e.g., Hyperion, CASI, and Headwall Micro-Hyperspec) with hundreds of bands can capture more detailed spectral responses; hence, it is more capable of detecting subtle variations of ground covers and their changes over time. Therefore, hyperspectral imagery can be used to address the aforementioned challenges and facilitate more accurate and timely detection of crop physiological status $[12,13]$. Previous studies have also demonstrated the superior performance of hyperspectral over multispectral images in monitoring vegetation properties, such as estimating the leaf area index (LAI) [14], discriminating crop types [15], retrieving crop biomass [16], and assessing leaf nitrogen content [17]. Despite its outstanding performance, hyperspectral imaging has been utilized comparatively less in operational agricultural applications in the past few decades due to the high cost of the sensors and imaging missions, and various technical challenges (e.g., low signal-to-noise ratio and large data volume) [18-21]. Although ground-based hyperspectral reflectance data can be quickly measured using a spectroradiometer (e.g., ASD Field Spec, Analytical Spectral Devices Inc., Boulder, CO, USA) and have been widely used for observing canopy- and leaf-level spectral features [22-24], such ground-based measurements are limited to a few numbers of field sites, and they cannot capture spatial variability across large areas. In contrast, hyperspectral imaging sensors are more convenient to acquire spatial variability of spectral information across a region.

In recent years, a wide range of mini-sized and low-cost hyperspectral sensors have been developed and are available for commercial use, such as Micro- and Nano-Hyperspec (Headwall Photonics Inc., Boston, MA, USA), HySpex VNIR (HySpex, Skedsmo, Skjetten, Norway), and FireflEYE (Cubert GmbH, Ulm, Germany) $[11,25]$. These sensors can be mounted on manned or unmanned airborne platforms (e.g., airplanes, helicopters, and unmanned aerial vehicles (UAVs)) for acquiring hyperspectral images and supporting various monitoring missions $[13,26,27]$. In addition, new spaceborne hyperspectral sensors have been launched recently, such as the DESIS—launched in 2018 [28] - and PRISMAlaunched in 2019 [29]—or will be launched in the next few years, such as EnMAP, with scheduled launching in 2020 [30,31]. Overall, increasingly more airborne or spaceborne hyperspectral images have become available, bringing unprecedented opportunities for better monitoring of ground targets, especially for better investigation of crop and soil variabilities and supporting precision agriculture. Therefore, a literature search was performed to examine if more research in using hyperspectral imaging for agricultural purposes had been published in recent years. Both Web of Science and Google Scholar were used for conducting the literature search with topics or keywords, including hyperspectral, imaging, agriculture, or farming, and publication over a 30-year time span (1990 to 2020). The searched results were further verified to ensure that each publication falls within the scope of hyperspectral imaging for agriculture applications. It was found that there was an increasing number of publications in recent years that used hyperspectral imaging for agricultural applications (Figure 1). Substantially more studies have been published in the recent decade (e.g., 245 articles published in 2011-2020) than that in the previous one (e.g., 97 published in 2001-2010). 


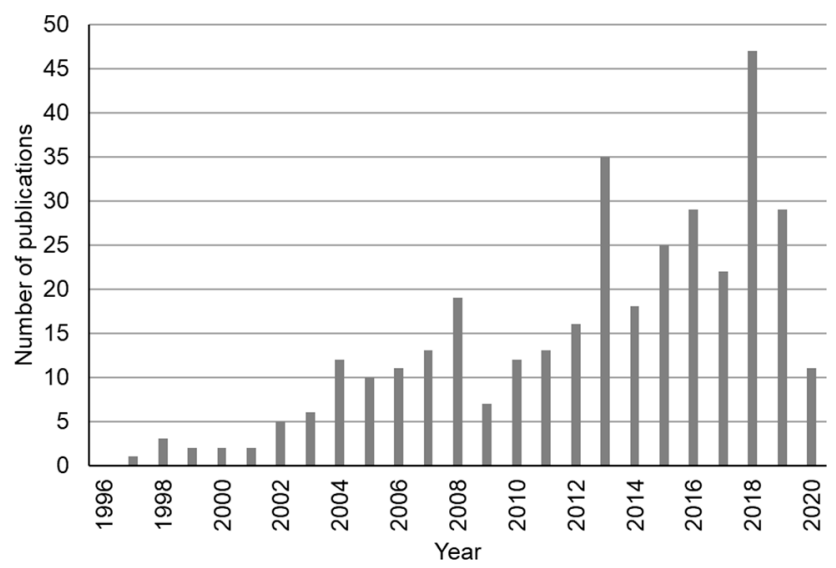

Figure 1. The number of publications that utilized hyperspectral imaging for agriculture applications (by May 2020).

This review is designed to focus on the acquisition, processing, and analysis of hyperspectral imagery for different agricultural applications. The review is organized in the following main aspects: (1) Hyperspectral imaging platforms and sensors, (2) methods for processing and analyzing hyperspectral images, and (3) hyperspectral applications in agriculture (Table 1). Regarding imaging platforms, different types, including satellites, airplanes, helicopters, fixed-wing UAVs, multi-rotor UAVs, and close-range platforms (e.g., ground or lab based), have been used. These platforms acquire images with different spatial coverage, spatial resolution, temporal resolution, operational complexity, and mission cost. It will be beneficial to summarize various platforms in terms of these features to support the selection of the appropriate one(s) for different monitoring purposes. After raw hyperspectral imagery is acquired, pre-processing is the step for obtaining accurate spectral information. Several procedures need to be carried out during pre-processing (usually implemented in a specialized remote sensing software), including radiometric calibration, spectral correction, atmospheric correction, and geometric correction. Although these are standard processing steps for most satellite imagery, it still can be challenging to perform on many airborne hyperspectral images due to different technical issues (e.g., the requirement of high-accuracy Global Positioning System (GPS) signals for proper geometric correction, the measurement of real-time solar radiance for accurate spectral correction). There are no standardized protocols for all sensors due to the limited availability of hyperspectral imaging in the past and the fact that the new mini-sized and low-cost hyperspectral sensors in the market are from different manufacturers with varying sensor configurations. Various approaches have been used in previous studies to address these challenges [12,19,32,33]. Therefore, it is essential to review these approaches to support other researchers for more accurate and efficient hyperspectral image processing. After pre-preprocessing, such as calibration and correction, spectral information extraction (e.g., band selection and dimension reduction) can be performed to further improve the usability of the hyperspectral image. Techniques for these procedures are reviewed in this study. 
Table 1. Topics reviewed in this article.

\begin{tabular}{llll}
\hline $\begin{array}{c}\text { Procedures of Applying } \\
\text { Hyperspectral Imagery }\end{array}$ & \multicolumn{1}{c}{ Image Acquisition } & Image Processing and Analysis & Image Applications \\
\hline & Platforms: & Pre-processing: & Specific Applications: \\
& - Satellites & - Geometric and radiometric & - Estimating crop biochemical and biophysical properties \\
& - Airplanes & correction etc. & - Evaluating crop nutrient status \\
& - UAVs & - Dimension reduction & - Classifying imagery to identify crop types, growing stages, \\
Review Focuses & - Close-range platforms & - Band selection & - Retrieving soil moisture, fertility, and other physical or \\
& Sensors: & Analytical Methods: & \\
& - EO-1 Hyperion & - Empirical regression & \\
& - AVIRIS & - Radiative transfer modelling & \\
& - CASI & - Machine learning and & \\
\hline
\end{tabular}


With pre-processed hyperspectral images, a robust and efficient analytical method is required for analyzing the tremendous amount of information contained in the images (e.g., spectral, spatial, and textural features) and extracting target properties (e.g., crop and soil characteristics). Previous studies have used a suite of analytical methods, including empirical regression (e.g., linear regression, partial least square regression (PLSR), and multi-variable regression (MLR)), radiative transfer modelling (RTM, e.g., PROSPECT and PROSAIL), machine learning (e.g., random forest (RF)), and deep learning (e.g., convolutional neural network (CNN)) [34-37]. These methods have been developed based on different theories and have different operational complexity, computation efficiency, and performance accuracy. Therefore, it is essential to review the strengths and limitations of these methods and help to choose the appropriate one(s) for specific research purposes. Using hyperspectral information, researchers have investigated a wide range of agricultural features. Some popular ones include crop water content, LAI, chlorophyll and nitrogen contents, pests and disease, plant height, phenological information, soil moisture, and soil organic matter content [11,38]. It will also be valuable to review the performances of hyperspectral imaging in these studies and further explore the potential of this technology for monitoring other agricultural features. Lastly, challenges of using hyperspectral imaging for precision agriculture, together with future research directions, are discussed. A few previous review articles have discussed some of these topics to some extent $[11,38,39]$. More details and contributions of this review will be discussed in each specific section. Overall, this review aims to examine the main procedures in collecting and utilizing hyperspectral images for different agricultural applications, to further understand the strengths and limitations of hyperspectral technology, and to promote the faster adoption of this valuable technology in precision farming.

\section{Hyperspectral Imaging Platforms and Sensors}

Hyperspectral sensors can be mounted on different platforms, such as satellites, airplanes, UAVs, and close-range platforms, to acquire images with different spatial and temporal resolutions. Platforms used in the literature were identified and summarized over the publication years, aiming to find, if any, the platforms that had been used more frequently in a specific time period, and the results are shown in Figure 2. Airplanes have been the most widely used platforms for hyperspectral imaging in agriculture (Figure 2). Approximately 30 articles that used airplanes were published every five years starting from 2001 (e.g., 27 publications in 2001-2005 and 38 in 2006-2010). In comparison, satellite-based hyperspectral imaging has been used less frequently; approximately 20 or fewer articles were published in all five-year periods. UAVs are popular platforms for remote sensing and have been widely used in the last decade for hyperspectral imaging in agriculture (e.g., more than 20 publications in 2011-2015 and 2016-2020). Close-range platforms have been the most widely used in the last five years (i.e., 2016-2020), with 49 publications (Figure 2). The review in this section is structured based on different platforms, including satellites, airplanes, UAVs, and close-range platforms. In contrast to previous articles reviewing hyperspectral platforms [20,38,39], the review in this section focuses more on recent advancements of imaging platforms (e.g., UAVs, helicopters, and close range) and their applications to precision farming (e.g., weed classification, fine-scale evaluation of crop health, pests, and disease).

\subsection{Satellite-Based Hyperspectral Imaging}

Compared with a large number of satellite-based multispectral sensors (e.g., Landsat, SPOT, WorldView, QuickBird, Sentinel-2), there are significantly fewer hyperspectral sensors. EO-1 Hyperion, PROBA-CHRIS, and TianGong-1 [40] are a few examples of the available satellite hyperspectral sensors [20]. EO-1 Hyperion is the most widely used satellite-based hyperspectral sensor for agriculture (e.g., more than 40 publications). It collects data in the visible, near-infrared, and shortwave infrared ranges with a spectral resolution of $10 \mathrm{~nm}$ and a spatial resolution of $30 \mathrm{~m}$. More sensor specifications of EO-1 Hyperion are given in Table 2. The sensor was in operation from 2000 to 2017, which corresponds to the period having more publications using satellite-based hyperspectral imaging (e.g., 2006 to 2020 in Figure 2). The use of Hyperion data has been reported in a 
variety of agricultural studies for monitoring different crop and soil properties, including detecting crop disease [41,42], estimating crop properties (e.g., chlorophyll, LAI, biomass) [43-45], assessing crop residues [46,47], classifying crop types [48], and investigating soil features [49,50]. A few featured ones include $\mathrm{Wu}$ et al. [45], who estimated vegetation chlorophyll content and LAI in a mixed agricultural field using Hyperion data and evaluated spectral bands that are sensitive to these vegetation properties. Camacho Velasco et al. [48] used Hyperion hyperspectral imagery and different classification algorithms (e.g., spectral angle mapper and adaptive coherence estimator) for identifying five types of crops (e.g., oil palm, rubber, grass for grazing, citrus, and sugar cane) in Colombia. Gomez et al. [49] predicted soil organic carbon (SOC) using both spectroradiometer data and a Hyperion hyperspectral image, and they found that using Hyperion data resulted in a lower accuracy compared with results derived from spectroradiometer data.

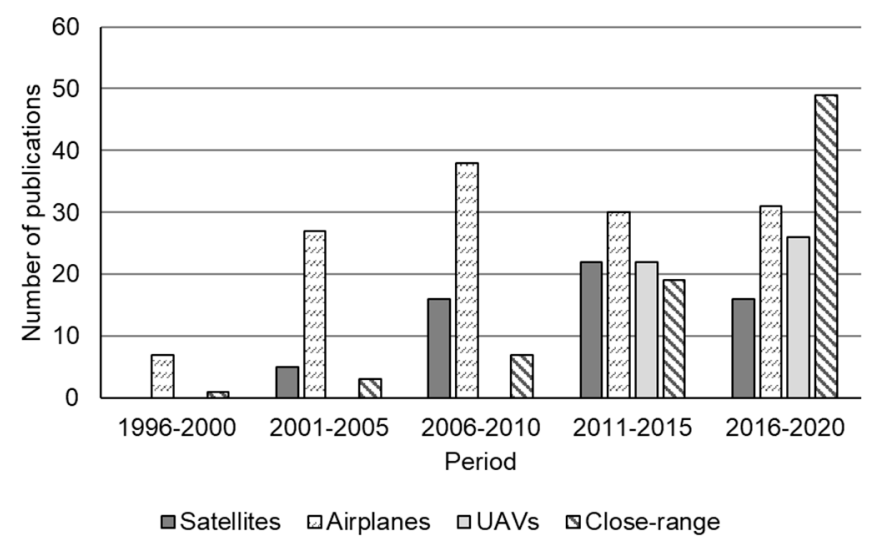

Figure 2. Number of publications that used different hyperspectral imaging platforms over time.

Studies have also been conducted to compare the performances of Hyperion hyperspectral imagery with multispectral imagery for estimating crop properties or classifying crop types. For instance, Mariotto et al. [15] compared Hyperion hyperspectral imagery with Landsat multispectral imagery for the estimation of crop productivity and the classification of crop types. The authors reported better performances of using hyperspectral imagery than using Landsat imagery for both research purposes. Similarly, Bostan et al. [51] compared Hyperion hyperspectral imagery with Landsat multispectral imagery for crop classification and also found that higher classification accuracy can be achieved by using hyperspectral imagery. 
Table 2. Specifications of commonly used hyperspectral sensors [11,20,52-56].

\begin{tabular}{|c|c|c|c|c|c|c|c|c|c|}
\hline \multirow[b]{2}{*}{ Sensor } & \multicolumn{3}{|c|}{ Satellite-Based } & \multicolumn{4}{|c|}{ Airplane-Based } & \multicolumn{2}{|c|}{ UAV-Based * } \\
\hline & Hyperion & PRC & IRIS & AVIRIS & CASI & AISA & HyMap & $\begin{array}{l}\text { Headwall } \\
\text { Hyperspec }\end{array}$ & $\begin{array}{c}\text { UHD } \\
\text { 185-Firefly }\end{array}$ \\
\hline Spectral range (nm) & $357-2576$ & \multicolumn{2}{|c|}{$415-1050$} & $400-2500$ & $\begin{array}{l}380-1050 \\
\text { (CASI-1500) }\end{array}$ & $\begin{array}{c}400-970 \\
\text { (Eagle) }\end{array}$ & $440-2500$ & $\begin{array}{l}400-1000 \\
\text { (VNIR) }\end{array}$ & $450-950$ \\
\hline Number of spectral bands & 220 & 19 & 63 & 224 & 288 & 244 & 128 & $\begin{array}{l}270 \text { (Nano) } \\
324 \text { (Micro) } \\
\end{array}$ & 138 \\
\hline Spectral Resolution (nm) & 10 & 34 & 17 & 10 & $<3.5$ & 3.3 & 15 & $\begin{array}{c}6 \text { (Nano) } 2.5 \\
\text { (Micro) }\end{array}$ & 4 \\
\hline Operational altitudes $(\mathrm{km})$ & 705 (swath 7.7 km) & \multicolumn{2}{|c|}{830 (swath 14 km) } & \multicolumn{4}{|c|}{$1-20$} & \multicolumn{2}{|c|}{$<0.15$} \\
\hline Spatial resolution (m) & 30 & 17 & 36 & \multicolumn{4}{|c|}{$1-20$} & \multicolumn{2}{|c|}{$0.01-0.5$} \\
\hline Temporal resolution (days) & $16-30$ & \multicolumn{2}{|c|}{8} & \multicolumn{6}{|c|}{ Depends on flight operations (hours to days) } \\
\hline Organization & NASA, USA & & & $\begin{array}{l}\text { Jet Propulsion } \\
\text { Laboratory, } \\
\text { USA }\end{array}$ & $\begin{array}{c}\text { Itres, } \\
\text { Canada }\end{array}$ & $\begin{array}{l}\text { Specim, } \\
\text { Finland }\end{array}$ & $\begin{array}{l}\text { Integrated } \\
\text { Spectronics, } \\
\text { Australia }\end{array}$ & $\begin{array}{l}\text { Headwall } \\
\text { Photonics, } \\
\text { USA }\end{array}$ & $\begin{array}{c}\text { Cubert GmbH, } \\
\text { Germany }\end{array}$ \\
\hline Number of publications & 41 & & & 18 & 22 & 20 & 12 & 9 & 6 \\
\hline
\end{tabular}

* UAV-based sensors typically can also be mounted on airplanes for imaging. 
PROBA-CHRIS is another commonly used satellite-based hyperspectral sensor that was launched in 2001. Specific studies, such as Verger et al. [57], utilized PROBA-CHRIS data for retrieving LAI, the fraction of vegetation cover (fCover), and the fraction of absorbed photosynthetically active radiation (FAPAR) in an agricultural field. Antony et al. [58] identified three growth stages of wheat using multi-angle PROBA-CHRIS images and found the optimal view angles for the identification. Casa et al. [59] evaluated the performance of airborne Multispectral Infrared Visible Imaging Spectrometer (MIVIS) data and spaceborne PROBA-CHRIS data for investigating soil texture, and they found that these two data have similar performances, although the PROBA-CHRIS data have a lower spatial resolution.

There are a few other satellite-based hyperspectral sensors that have not been commonly used in an agricultural environment. For instance, Hyperspectral Imager (HySI) is a hyperspectral sensor equipped on the Indian Microsatellite-1 (IMS-1) launched in 2008 [60]. It collects spectral signals in the range of 400-950 $\mathrm{nm}$ with a spatial resolution of $550 \mathrm{~m}$ at nadir [61]. HySI imagery has been used to map different agricultural features, such as soil moisture and soil salinity [62]. It has also been used for crop classification [63]. However, this data has not been widely used in precision farming, which is probably due to the low spatial resolution and limited data availability. The Hyperspectral Imager for the Coastal Ocean (HICO) is another spaceborne hyperspectral sensor that takes images with a spectral range from 380 to $960 \mathrm{~nm}$ at a spatial resolution of $90 \mathrm{~m}$ [64]. This sensor was mainly designed to sample the coastal ocean and operated from 2009 to 2015.

In recent years, several spaceborne hyperspectral sensors have been launched or scheduled for launching in the next few years. For instance, the German Aerospace Center (DLR) Earth Sensing Imaging Spectrometer (DESIS), a hyperspectral sensor mounted on the International Space Station, was launched in 2018 [65]. This sensor acquires images in the range from 400 to $1000 \mathrm{~nm}$ with a spectral resolution of $2.5 \mathrm{~nm}$ and a spatial resolution of $30 \mathrm{~m}$. The Hyperspectral Imager Suite (HISUI) is a Japanese hyperspectral sensor that is also onboard the International Space Station [66]. It was launched in 2019 and collects data in the range from 400 to $2500 \mathrm{~nm}$ with a spatial resolution of $20 \mathrm{~m}$ and a temporal resolution of 2 to 60 days [20]. Hyperspectral Precursor and Application Mission (PRISMA) is an Italian hyperspectral mission with the sensor launched in March 2019. Its spectral resolution is $12 \mathrm{~nm}$ in the range of $400-2500 \mathrm{~nm}(\sim 250$ bands in visible to shortwave infrared). Its hyperspectral imagery has a spatial resolution of 30 and $5 \mathrm{~m}$ for the panchromatic band [67]. The Environmental Mapping and Analysis Program (EnMAP) is a German hyperspectral satellite mission that is still in the development and production phase [68]. The EnMAP sensor will collect data from the visible to the shortwave infrared range with a spatial resolution of $30 \mathrm{~m}$. It is planned to be launched in 2020 . The Spaceborne Hyperspectral Applicative Land and Ocean Mission (SHALOM) is a joint mission by Israeli and Italian space agencies, and the satellite is scheduled to be launched in 2022 [69]. This sensor will collect hyperspectral images with a spatial resolution of $10 \mathrm{~m}$ in the spectral range of 400-2500 nm and panchromatic images with a spatial resolution of $2.5 \mathrm{~m}$ [70]. HyspIRI is another hyperspectral mission that is also at the study stage [71]. This sensor will collect data in the 380 to $2500 \mathrm{~nm}$ range with an interval of $10 \mathrm{~nm}$ and a spatial resolution of $60 \mathrm{~m}$.

Although the actual PRISMA, EnMAP, and HyspIRI data are not yet available, researchers have simulated the images using other data and tested the performance of the simulated images for investigating different vegetation and soil features. For instance, Malec et al. [72], Siegmann et al. [73], and Locherer et al. [74] simulated EnMAP imagery using different airborne or spaceborne images and applied the simulated images for investigating different crop and soil properties. Bachmann et al. [75] produced an image using the EnMAP's end-to-end simulation tool and examined the uncertainties associated with spectral and radiometric calibration. Castaldi et al. [76] simulated data of four current (EO-1 ALI and Hyperion, Landsat 8 Operational Land Imager (OLI), Sentinel-2 MultiSpectral Instrument (MSI)) and three forthcoming (EnMAP, PRISMA, and HyspIRI) sensors using a soil spectral library and compared their performance for estimating soil properties. Castaldi et al. [77] used PRISMA 
data that were simulated with lab-measured spectral data for estimating clay content and attempted to reduce the influence of soil moisture on the estimation of clay.

Previous studies have confirmed the good performance of satellite-based hyperspectral sensors for studying agricultural features; however, several factors could potentially affect the broad applications of these data in precision farming, including the spatial resolution, temporal resolution, and data quality. The detection and monitoring of many agricultural features, such as crop disease, pest infestation, and nutrient status, require high spatial and temporal resolution. Most of the satellite-based hyperspectral sensors have medium spatial resolutions, such as 17 or $36 \mathrm{~m}$ for PROBA-CHRIS; $30 \mathrm{~m}$ for Hyperion, PRISMA, and EnMAP, DESIS; and $60 \mathrm{~m}$ for HyspIRI. Previous studies have indicated that such spatial resolutions are not sufficient for precision farming applications $[20,49]$. To overcome such limitations, researchers have attempted to pansharpen hyperspectral images, aiming to improve spatial resolution [73,78-80]. Loncan et al. [81] also reviewed different pansharpening methods for generating high-spatial resolution hyperspectral images.

Temporal resolution is another factor that could potentially limit the applications of satellite-based hyperspectral images to precision agriculture. Most of the satellite-based sensors have a long revisit cycle (e.g., typically around two weeks), and thus early signals of crop stress (e.g., disease and pest) may be missed. This limitation can be further aggravated by unfavorable weather conditions (e.g., cloud contamination). Lastly, low data quality is also an issue that can affect the performance of satellite-based hyperspectral imaging for investigating agricultural features. A low signal-to-noise ratio is a well-known issue of Hyperion data (e.g., in the shortwave infrared (SWIR) range), which has affected the accuracy of retrieving different agricultural features [20]. For instance, Asner and Heidebrecht [82], Gomez et al. [49], and Weng et al. [83] found that the low signal-to-noise ratio influenced the accuracies of estimating non-photosynthetic vegetation and soil cover, soil organic matter, and soil salinity, respectively. Future satellite-based hyperspectral missions are expected to solve the data quality issue.

\subsection{Airplane-Based Hyperspectral Imaging}

Airborne hyperspectral imaging has been widely used to collect hyperspectral imagery for different monitoring purposes (e.g., for agriculture or forestry). The first hyperspectral sensor was an airborne visible/infrared imaging spectrometer (AVIRIS) that was developed and utilized in 1987 [84]. It collects spectral signals in 224 bands in the visible to SWIR range (Table 2). Researchers have applied AVIRIS data to help understand a wide range of agricultural features, such as investigating vegetation properties (e.g., yield, LAI, chlorophyll, and water content) [85-88], analyzing soil properties [89], evaluating crop health or identifying pest infestation [90-92], and mapping crop area or agricultural tillage practices $[93,94]$.

Besides AVIRIS, the Compact Airborne Spectrographic Imager (CASI), Hyperspectral Mapper (HyMap), and AISA Eagle are also widely used airborne hyperspectral sensors (Table 2). For instance, CASI images have been used for estimating crop chlorophyll content [95], investigating crop cover fraction [96], classifying weeds [97], and delineating management zones [2]. The HyMap imagery has been applied to examining crop biophysical and biochemical variables (e.g., LAI, chlorophyll and water content) [98-100], detecting plant stress signals [101], and investigating the spatial patterns of SOC [102]. Regarding AISA Eagle imagery, Ryu et al. [35] and Cilia et al. [103] used this data for estimating crop nitrogen content, and Ambrus et al. [104] used it for estimating biomass.

Several other airborne hyperspectral sensors have also been used in previous studies. For instance, AVIS images were used for investigating a range of vegetation characteristics (e.g., biomass and chlorophyll) [105], Probe-1 hyperspectral images were used for investigating crop residues [106], RDACS-H4 hyperspectral images were used for detecting crop disease [34], AHS-160 hyperspectral sensor was used for mapping SOC [107], the SWIR Hyper Spectral Imaging (HSI) sensor was used for estimating soil moisture [108], the Pushbroom Hyperspectral Imager (PHI) was used for estimating winter wheat LAI [109], and airborne prism experiment (APEX) data were used for studying the relationship between SOC in croplands and the spectral signals [110]. 
Most of the aforementioned airborne hyperspectral images have been acquired by airplanes at medium to high altitude (e.g., 1-4 km altitude for CASI, $20 \mathrm{~km}$ for AVIRIS), and the acquired images generally having high to medium spatial resolution, such as $4 \mathrm{~m}$ for CASI imagery, $5 \mathrm{~m}$ for HyMap, and $20 \mathrm{~m}$ for AVIRIS [111-113]. Such spatial resolutions are appropriate for mapping many crop and soil features. However, image acquisition usually needs to be scheduled months or even years in advance, and flight missions are expensive [19]. Furthermore, for some specific applications, such as investigating species-level or community-level features (e.g., identification of weeds or early signal of crop disease), images with very high spatial resolutions (e.g., sub-meter) are preferred [114,115]. In addition, due to the unstable nature of airplanes as imaging platforms, a gimbal or high-accuracy inertial measurement unit (IMU) will be required to compensate for the orientation change of the airplanes or recording the orientation information for subsequent image correction, respectively. These factors limited the full application of airborne hyperspectral imaging in precision agriculture. Manned helicopters have also been used as platforms for hyperspectral imaging and investigation of vegetation features [27,116]. Helicopters have more flexible flight heights (e.g., $100 \mathrm{~m}-2 \mathrm{~km}$ ) than airplanes and are capable of acquiring high-spatial-resolution images (e.g., sub-meter) over large areas. An aviation company with a manned helicopter is generally needed for the imaging task, which requires extra funding support and far advanced pre-scheduling.

\subsection{UAV-Based Hyperspectral Imaging}

UAV has become a popular platform in recent years for remote sensing data acquisition, especially for multispectral imaging using digital cameras or multispectral sensors. With the increased availability of lightweight hyperspectral sensors, researchers have experimented on mounting these sensors on UAVs to acquire high-spatial-resolution hyperspectral imagery [19,117]. Different types of UAVs, including multi-rotors, helicopters, and fixed wings, have been utilized in previous studies (Figure 3). Compared with manned airplanes and helicopters, UAVs are capable of acquiring highspatial-resolution images with a much lower cost and have high flexibility in terms of scheduling a flight mission [118]. Several specific agricultural applications of UAV-based hyperspectral imaging are summarized in Table 3.
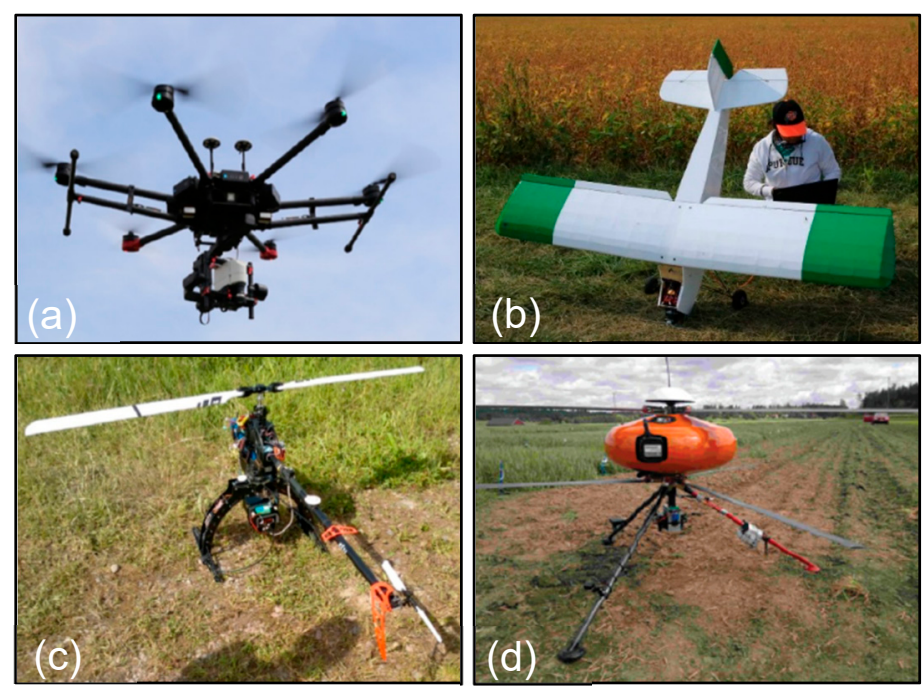

Figure 3. Hyperspectral UAV systems used in previous agricultural studies. Figures were reproduced with permission from the corresponding publishers: (a) MDPI [119], (b) MDPI [120], (c) MDPI [121], and (d) SPIE [122]. 
Table 3. Example applications of UAV-based hyperspectral imaging in agriculture.

\begin{tabular}{|c|c|c|}
\hline Applications & Previous Studies & Research Focuses \\
\hline $\begin{array}{l}\text { Estimating LAI and } \\
\text { chlorophyll }\end{array}$ & Yu et al. [37] & $\begin{array}{l}\text { Estimated a range of vegetation phenotyping variables } \\
\text { (e.g., LAI and leaf chlorophyll) using UAV-based } \\
\text { hyperspectral imagery and radiative transfer modelling. }\end{array}$ \\
\hline \multirow[t]{2}{*}{ Estimating biomass } & Honkavaara et al. [123] & $\begin{array}{l}\text { Mounted a hyperspectral sensor and a consumer-level } \\
\text { camera on a UAV for estimating biomass in a wheat and } \\
\text { a barley field. }\end{array}$ \\
\hline & Yue et al. [124] & $\begin{array}{l}\text { Utilized UAV-based hyperspectral images for estimating } \\
\text { winter wheat above-ground biomass. }\end{array}$ \\
\hline \multirow{3}{*}{$\begin{array}{l}\text { Estimating nitrogen } \\
\text { content }\end{array}$} & Pölönen et al. [125] & $\begin{array}{l}\text { Used lightweight UAVs for collecting hyperspectral } \\
\text { images and estimated crop biomass and nitrogen content. }\end{array}$ \\
\hline & Kaivosoja et al. [126] & $\begin{array}{l}\text { Applied UAV-based hyperspectral imagery to investigate } \\
\text { biomass and nitrogen contents in a wheat field. }\end{array}$ \\
\hline & Akhtman et al. [127] & $\begin{array}{l}\text { Utilized UAV-based hyperspectral images for estimating } \\
\text { nitrogen content and phytomass in corn and wheat fields } \\
\text { and monitored temporal variations of these properties. }\end{array}$ \\
\hline $\begin{array}{l}\text { Estimating water } \\
\text { content }\end{array}$ & Izzo et al. [128] & $\begin{array}{l}\text { Evaluated water content in the commercial vineyard } \\
\text { using UAV-based hyperspectral images and determined } \\
\text { wavelengths sensitive to canopy water content. }\end{array}$ \\
\hline Classifying weeds & Scherrer et al. [129] & $\begin{array}{l}\text { Classified herbicide-resistant weeds in different crop } \\
\text { fields (e.g., barley, corn, and dry pea) using both ground } \\
\text { and UAV-based hyperspectral imagery. }\end{array}$ \\
\hline Detecting disease & Bohnenkamp et al. [119] & $\begin{array}{l}\text { Used both ground- and UAV-based hyperspectral images } \\
\text { for detecting yellow rust in wheat. }\end{array}$ \\
\hline
\end{tabular}

Various lightweight hyperspectral sensors have been developed in recent years and can be mounted on UAVs. Examples of sensors include the widely-used Headwall Micro- and Nano-Hyperspec VNIR [12,13,26,128], UHD 185-Firefly [53,130], the PIKA II sensor [19,32], and the HySpex VNIR [25,131]. These hyperspectral sensors contain more than 100 bands in the visible-near infrared spectral range (Table 2). These sensors are small and compact (1-2 kg), thus they can be deployed quickly on various manned or unmanned remote sensing platforms. Previous studies conducted by Adão et al. [11] and Lodhi et al. [52] also compared and summarized various lightweight hyperspectral sensors.

A large number of factors need to be considered in the application of UAV-based hyperspectral imaging, ranging from sensor setup and data collection, to image processing. Saari et al. [122] tested the feasibility of a UAV-based hyperspectral imaging system for agricultural and forest applications and discussed several challenges regarding the imaging technology (e.g., hardware requirements and system settings). Aasen et al. [132] focused on the calibration of images collected with a frame-based sensor and discussed several challenges related to the use of UAV-based hyperspectral imaging for vegetation and crop investigation (e.g., the payload of UAV, signal-to-noise ratio, and spectral calibration). Habib et al. [120] attempted to perform orthorectification of UAV-acquired pushbroom-based hyperspectral imagery with frame-based RGB images over an agricultural field. Adão et al. [11] reviewed applications of UAV-based hyperspectral imaging in agriculture and forestry and listed several hyperspectral sensors that can be mounted on UAVs. The authors also discussed several challenges in collecting and analyzing UAV-based hyperspectral imagery, such as radiometric noise, the low quality of UAV georeferencing, and a low signal-to-noise ratio.

UAV-based hyperspectral imaging has become more popular in recent years; therefore, it is critical to review its strengths and limitations. To explore more features of this technology, this section of the review is not limited to agricultural applications alone. Different types of UAVs have been used as hyperspectral imaging platforms, with the two most widely used as multi-rotors $[130,133,134]$ and fixed-wing planes $[33,120,135]$. Slow flights at low altitudes are preferred to achieve high-spatial-resolution hyperspectral imagery with a high signal-to-noise ratio. Thus, a multi-rotor is more competitive than 
fixed-wing planes for hyperspectral imaging in terms of flight operation. Specifically, the multi-rotor allows for a low flight altitude, flexible flight speed, and vertical takeoff and landing, while the fixed wing requires a minimum flight altitude, speed, and, sometimes, accessories for takeoff and landing (e.g., runway, launcher, and parachute). A hyperspectral imaging system, which consists of a hyperspectral sensor, a data processing unit, a GPS, and an IMU, has a considerable weight (e.g., 1-3 kg), thus bringing challenges to the payload capacity of the UAV system and its battery endurance. The multi-rotors are generally powered by high-performance batteries (e.g., LiPo), and most have a short endurance (e.g., less than $20 \mathrm{~min}$ ). The endurance can be as short as $3 \mathrm{~min}$ [12]. In contrast, many fixed-wing UAVs are powered by fuel, thus having a much longer endurance (e.g., 1-10 h) $[19,135]$. However, these fixed-wing planes are mostly large and heavy (e.g., a $5 \mathrm{~m}$ wingspan and $14 \mathrm{~kg}$ take-off weight) [135], and thus bring challenges to the flight operation. Using UAV, researchers need to consider the UAV SWaP (size, weight, and power), geographical coverage, time aloft, altitude, and other variables. In addition to the challenges in building a UAV system and performing flight operations, researchers likely need to apply for flight permission from an aviation authority (e.g., Special Flight Operations Certificate (SFOC) from Transport Canada), and purchase suitable UAV flight insurance [136]. UAV size and weight are essential parameters to consider in these processes. Furthermore, the UAVs are required to be visible during flight missions, so that the pilot can maintain constant visual contact with the aircraft. This could create a major challenge when flying over a large area, a hilly area, or an area with forests.

\subsection{Close-Range (Ground- or Lab-Based) Hyperspectral Imaging}

Close-range hyperspectral imaging, including ground (Figure 4a-c) or lab based (Figure $4 d, e$ ), is an emerging technology in recent years, and it is capable of acquiring super-high-spatial-resolution (e.g., cm or sub-cm level) hyperspectral imagery [137-139]. Therefore, this imaging technology can be used for investigating fine-scale (e.g., leaf and canopy level) vegetation features and thus greatly support the investigation of crop growing status and detection of early signs of crop stress (e.g., disease, weeds, or nutrition deficiency). Sensors are mounted on moving or static platforms (e.g., linear stages, scaffolds, or trucks) that can be deployed indoors or outdoors for collecting images. Lamps (e.g., halogen lamp) or the sun are used as light sources in these platforms, respectively.

Researchers have utilized different types of platforms and hyperspectral sensors for collecting super-high-spatial-resolution hyperspectral imagery to study different agricultural features, as shown in Table 4.

Table 4. Example applications of close-range hyperspectral imaging in previous studies.

\begin{tabular}{|c|c|c|}
\hline Applications & Previous Studies & Research Focuses \\
\hline \multirow{3}{*}{$\begin{array}{l}\text { Investigating } \\
\text { biochemical } \\
\text { components }\end{array}$} & Feng et al. [140] & $\begin{array}{l}\text { Designed a hyperspectral imaging system that consists of a } \\
\text { Headwall hyperspectral camera, a halogen lamp, a computer, } \\
\text { and a translation stage and used this system for taking images of } \\
\text { rice leaves to study leaf chlorophyll distribution. }\end{array}$ \\
\hline & Mohd Asaari et al. [141] & $\begin{array}{c}\text { Mounted a visible and near-infrared HIS camera in a } \\
\text { high-throughput plant phenotyping platform for evaluating } \\
\text { plant water status and detecting early stage signs of plant } \\
\text { drought stress. }\end{array}$ \\
\hline & Zhu et al. [142] & $\begin{array}{c}\text { Installed a hyperspectral camera and halogen lamp on a moving } \\
\text { stage and used this imaging system for estimating sugar and } \\
\text { nitrogen contents in tomato leaves. }\end{array}$ \\
\hline \multirow{2}{*}{$\begin{array}{l}\text { Detecting crop } \\
\text { disease }\end{array}$} & Morel et al. [143] & $\begin{array}{c}\text { Used a HySpex hyperspectral camera installed in a close-range } \\
\text { imaging system for investigating black leaf streak disease in } \\
\text { banana leaves. }\end{array}$ \\
\hline & Nagasubramanian et al. [144] & $\begin{array}{l}\text { Integrated a Pika XC hyperspectral line imaging scanner and } \\
\text { halogen illumination lamps for taking images of soybeans and } \\
\text { monitoring fungal disease. }\end{array}$ \\
\hline
\end{tabular}


Table 4. Cont.

\begin{tabular}{|c|c|c|}
\hline Applications & Previous Studies & Research Focuses \\
\hline \multirow{2}{*}{$\begin{array}{l}\text { Identifying } \\
\text { vegetation } \\
\text { species or } \\
\text { weeds }\end{array}$} & Eddy et al. [139] & $\begin{array}{l}\text { Mounted a hyperspectral sensor on a boom arm that was } \\
\text { installed on a truck for acquiring images at } 1 \mathrm{~m} \text { above the } \\
\text { ground and applied the hyperspectral images to classifying } \\
\text { weeds in different crop fields. }\end{array}$ \\
\hline & Lopatin et al. [145] & $\begin{array}{l}\text { Installed an AISA Eagle imaging spectrometer on a scaffold at } \\
\text { the height of } 2.5 \mathrm{~m} \text { above ground, aiming to collect hyperspectral } \\
\text { imagery in a grassland area for classifying grassland species. }\end{array}$ \\
\hline Phenotyping & Behmann et al. [146] & $\begin{array}{l}\text { Utilized hyperspectral cameras and a close-range 3D laser } \\
\text { scanner that were mounted on a linear stage for collecting } \\
\text { hyperspectral images and 3D point models, respectively, and } \\
\text { used these two datasets for generating hyperspectral 3D plant } \\
\text { models for better monitoring plant phenotyping features. }\end{array}$ \\
\hline \multirow{2}{*}{$\begin{array}{l}\text { Monitoring soil } \\
\text { properties }\end{array}$} & Antonucci et al. [147] & $\begin{array}{l}\text { Attempted to estimate copper concentration in contaminated } \\
\text { soils using hyperspectral images that were acquired from a } \\
\text { lab-based spectral scanner. }\end{array}$ \\
\hline & Malmir et al. [137] & $\begin{array}{c}\text { Collected close-range soil images using Pika XC2 hyperspectral } \\
\text { camera that was mounted on a linear stage and used the } \\
\text { hyperspectral imagery for investigating soil macro- and } \\
\text { micro-elements. }\end{array}$ \\
\hline
\end{tabular}

Overall, the close-range hyperspectral imaging platform is capable of acquiring super-highspatial-resolution hyperspectral imagery that is critical for investigating fine-scale crop or soil features. These features provide detailed information about the plant's biophysical and biochemical processes and how plants respond to environmental stresses and diseases. However, the image collection and processing also suffer from different issues, such as uninformative variability caused by the interaction of light with the plant structure (i.e., illumination effects), influences of shadows, and expanding applications of the platform to a large scale $[141,146]$. Further research in these areas is warranted.

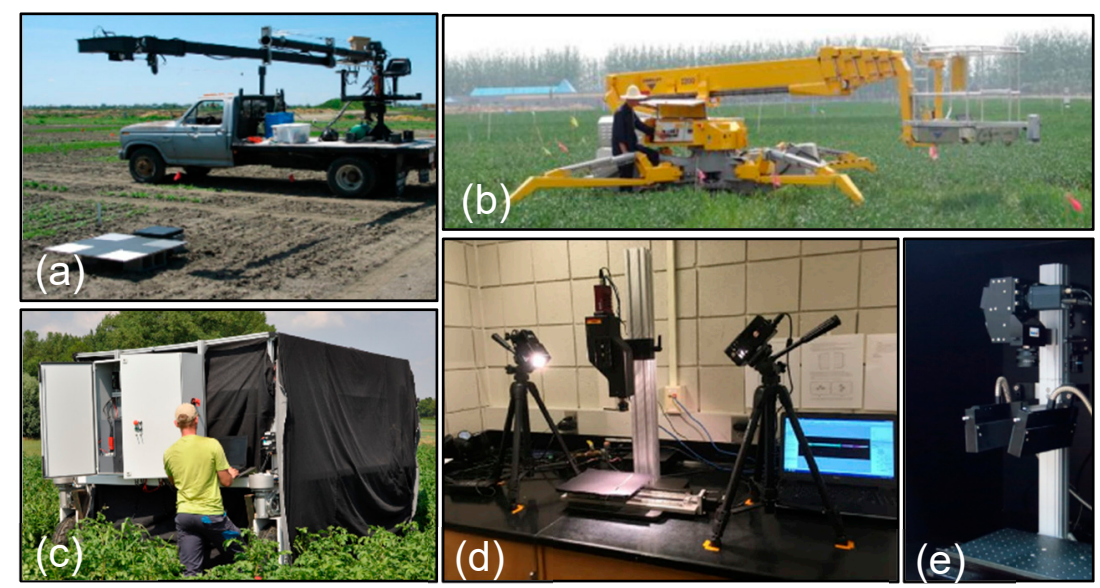

Figure 4. Close-range imaging platforms used in previous studies. Figures were reproduced with permission from corresponding publishers: (a) American Society for Photogrammetry and Remote Sensing (ASPRS), Bethesda, Maryland, asprs.org [139]; (b) SPIE [148]; (c) Elsevier [138]; (d) Springer Nature [144]; (e) Elsevier [149].

In summary, different hyperspectral imaging platforms, including satellites, airplanes, helicopters, UAVs, and close-range, have different advantages and disadvantages for applications in precision agriculture. Detailed comparisons of these platforms for agricultural applications are shown in Table 5. In brief, satellite-based systems provide images covering large areas but suffer from medium spatial resolution and limited data availability (e.g., a limited number of operating sensors and long 
revisit time). Airplane- and helicopter-based imaging platforms acquire data with suitable spatial coverage and resolution for most of the agricultural applications. However, they are limited by a high mission cost and scheduling challenges and thus are not suitable for repeated monitoring. UAV-based systems are capable of acquiring high-spatial resolution images repeatedly and have high flexibility. However, they can only cover a small area due to the limited battery endurance and aviation regulations. The close-range imaging systems are capable of obtaining super-high-spatial-resolution images, but they can only be used at leaf or canopy levels. Therefore, the following factors should be taken into consideration when selecting a platform for a specific research project: spatial resolution needed for the study, flight area and flight endurance, weight of the imaging system, platform payload capacity, flight safety and regulations, operation flexibility, and cost.

Table 5. Comparison of hyperspectral imaging platforms.

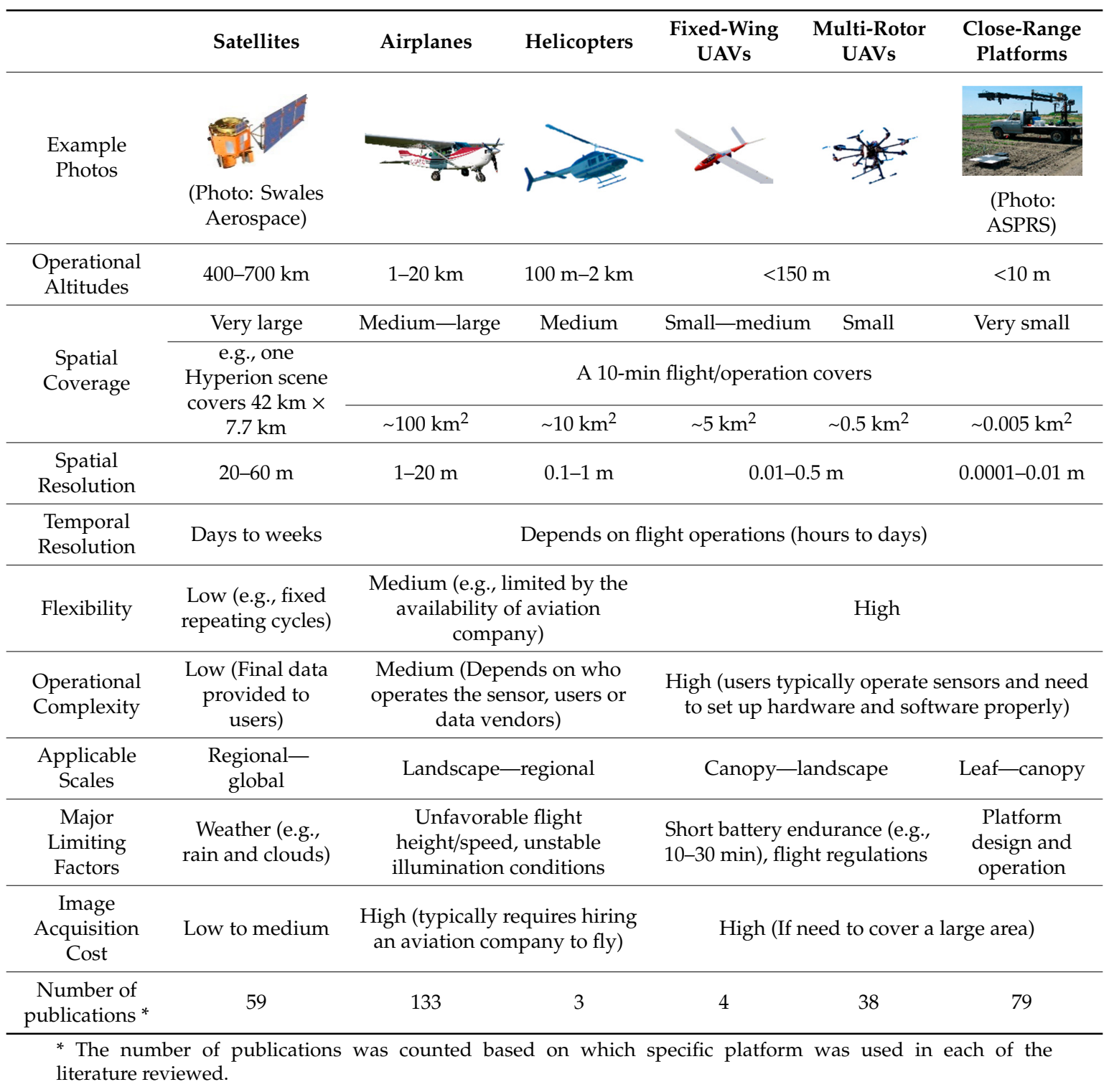

\section{Methods for Processing and Analyzing Hyperspectral Images}

Hyperspectral images acquired by different platforms and sensors are typically provided in a raw format (e.g., digital numbers) that needs to be pre-processed (e.g., atmospheric, radiometric, and spectral corrections) to retrieve accurate spectral information. Afterward, different approaches can be used for analyzing the hyperspectral information and investigating various agricultural features 
(e.g., crop and soil properties). A few commonly used methods include linear regression, advanced regression (e.g., PLSR), machine learning and deep learning (e.g., RF, CNN), and radiative transfer modelling (e.g., PROSPECT and PROSAIL). Researchers have used one or more of these methods for investigations of different agricultural features. In this section, the review is arranged based on the different methods used in the studies.

\subsection{Pre-Processing of Hyperspectral Images}

Typical processing of hyperspectral imagery includes geometric correction, orthorectification, radiometric correction, and atmospheric correction. For satellite- and airplane-based hyperspectral images, the geometric and orthorectification correction are generally performed by data providers, and the radiometric and atmospheric corrections can be done following standard image processing steps available in remote sensing software. For UAV-based images, in contrast, the users need to conduct these processing steps and decide on appropriate processing methods and associated parameters. For instance, a digital elevation model (DEM) and ground control points (GCPs) are usually needed for performing the orthorectification and geometric correction [12]. If the sensor mounted on UAV is pushbroom based, accurate sensor orientation information recorded by an IMU will be needed for these corrections, and the IMU needs to be integrated into the UAV and well-calibrated [12,27]. Software packages commonly used in previous studies for performing these corrections on UAV-based hyperspectral images include ENVI (Exelis Visual Information Solutions, Boulder, CO, USA) and PARGE (ReSe Applications Schläpfer, Wil, Switzerland) [12,26,117].

Radiometric correction is conducted to convert image digital numbers to radiance using calibration coefficients that are provided by the sensor manufacturer [11]. These coefficients may need to be updated over time due to the degradation of spectral materials used to construct the hyperspectral sensors. Regarding atmospheric correction, although the UAVs are flown at low altitudes, the signals acquired are still subjective to the influence of various atmospheric absorptions and scatterings, such as oxygen absorption at 760nm; water absorption near 820,940, 1140, 1380, and $1880 \mathrm{~nm}$; and carbon dioxide absorption at 2010 and $2060 \mathrm{~nm}[12,13,26,150]$. Therefore, atmospheric correction is critical for obtaining good-quality spectral information. However, Adão et al. [11] suggest that this process might be skipped if the UAVs are operated close to the ground. Therefore, the application of atmospheric correction will depend on specific flight missions and research purposes (e.g., flight altitudes, if atmosphere-influenced spectral bands are needed). Software or methods commonly used in previous studies for performing atmospheric correction on UAV-based hyperspectral images include the MODTRAN model (Spectral Sciences Inc.), ENVI FLAASH (L3Harris Geospatial), PCI Geomatica (PCI Geomatics Corporate), SMARTS model (Solar Consulting Services), and empirical line correction [12,19,27,32,33,116].

Hyperspectral images typically have hundreds of bands, and many of them are highly correlated. Therefore, dimension reduction is also an essential procedure to consider in the pre-processing of hyperspectral imagery. Many previous studies using hyperspectral imagery have discussed the challenges of data redundancy and have used different methods for dimension reduction. For instance, Miglani et al. [151] performed principal component analysis (PCA) on hyperspectral images and indicated that $99 \%$ of the information could be explained in the first 10 principal components. Amato et al. [152] discussed a few previous methods of dimension reduction, such as PCA, minimum noise fraction (MNF), and singular value decomposition (SVD), and proposed a dimension reduction algorithm based on discriminant analysis for supervised classification. Teke et al. [38] reviewed several dimension reduction methods and summarized them based on transformation techniques. Thenkabail et al. [153] discussed the problems of high dimensionality and listed a number of spectral bands that are more important for investigating crop features. Sahoo et al. [4] reviewed different methods for dimension reduction, such as PCA, uniform feature design (UMD), wavelet transforms, and artificial neural networks (ANNs), and discussed their features of operation. Wang et al. [154] proposed an auto-encoder-based dimensionality reduction method that is a deep learning-based approach. Of these different methods, the wavelet transform is one of the most widely used ones for 
dimension reduction. This technique decomposes a signal into a series of scaled versions of the mother wavelet function and allows the variation of the wavelet based on the frequency information to extract localized features (e.g., local spectral variation) [155,156]. It has also been successfully used for image fusion, feature extraction, and image classification [156-158].

In addition to dimensionality reduction, band sensitivity analysis and band selection have also been widely used in hyperspectral remote sensing to reduce the data size by selecting only the bands that are sensitive to the object of interest. Different algorithms have been proposed in previous studies for band selection, such as a fast volume-gradient-based method that is an unsupervised method and removes the most redundant band successively based on the gradient of volume [159], a column subset selection-based method that maximizes the volume of the selected subset of columns (i.e., bands) and is robust to noisy bands [160], and a manifold ranking-based salient band selection method that puts band vectors in manifold space and selects a band-based ranking that can tackle the problem of inappropriate measurement of the band difference [161]. With the sensitivity analysis, previous studies have identified spectral bands that are sensitive to different crop properties, for instance, $\sim 515, \sim 550$, $\sim 570, \sim 670,700-740, \sim 800$, and $\sim 855 \mathrm{~nm}$ for investigating chlorophyll content; $405, \sim 515, \sim 570, \sim 705$, and $\sim 720 \mathrm{~nm}$ for evaluating nitrogen status; $\sim 970, \sim 1180, \sim 1245, \sim 1450$, and $\sim 1950 \mathrm{~nm}$ for assessing water content; $\sim 682, \sim 855, \sim 910, \sim 970, \sim 1075, \sim 1245, \sim 1518, \sim 1725$, and $\sim 2260 \mathrm{~nm}$ for estimating biomass; and $\sim 550, \sim 682, \sim 855, \sim 1075, \sim 1180, \sim 1450$, and $\sim 1725 \mathrm{~nm}$ for crop classification $[36,44,153,162]$. Overall, pre-processing is an essential step for improving the quality of hyperspectral images and preparing for further data analysis. After the pre-processing, the analytical methods to be discussed below can be used for analyzing the hyperspectral information and investigating various agricultural features on the ground.

\subsection{Empirical Relationships}

Linear regression is a widely used method for analyzing hyperspectral imagery and retrieving target information (e.g., crop and soil properties). Both spectral reflectance and vegetation indices can be used as predictor variables in establishing a linear relationship. For instance, using spectral bands, Finn et al. [108] built linear regressions between field-measured soil moisture data and the spectral reflectance of collected hyperspectral imagery and identified bands that have stronger correlations with soil moisture. More studies have used vegetation indices in the regression for a better performance as some indices can enhance the signal of targeted features and minimize the background noise. Some of the previous studies are shown in Table 6.

Table 6. Selected previous studies utilized linear regression and hyperspectral vegetation indices for investigating agricultural features.

\begin{tabular}{ccc}
\hline Applications & Previous Studies & Research Focuses \\
\hline & & Utilized the Chlorophyll Absorption Integral (CAI), Optimized \\
& Oppelt and Mauser [105] & $\begin{array}{c}\text { Soil-Adjusted Vegetation Index (OSAVI), and hyperspectral } \\
\text { Normalized Difference Vegetation Index (h NDVI) for estimating } \\
\text { leaf chlorophyll and nitrogen content from hyperspectral } \\
\text { imagery and evaluated the performance of each of the indices. }\end{array}$ \\
\cline { 2 - 3 } $\begin{array}{c}\text { Estimating leaf } \\
\text { chlorophyll and } \\
\text { nitrogen content }\end{array}$ & Tested a range of vegetation indices (e.g., NDVI, Simple Ratio \\
& (SR), and Triangular Vegetation Index (TVI)) for retrieving \\
& & vegetation chlorophyll content and LAI from Hyperion images \\
& & and determined the indices that produced high accuracies. \\
& & Utilized the Double-peak Canopy Nitrogen Index (DCNI) and \\
& Modified Chlorophyll Absorption Ratio Index/Modified \\
& Triangular Vegetation Index 2 (MCARI/MTVI2) for estimating \\
& nitrogen content, as well as the Transformed Chlorophyll \\
& Absorption in Reflectance Index (TCARI), MERIS Terrestrial \\
& Chlorophyll Index (MTCI) and Triangular Chlorophyll Index \\
& (TCI) for estimating leaf pigments. \\
\hline
\end{tabular}


Table 6. Cont.

\begin{tabular}{|c|c|c|}
\hline Applications & Previous Studies & Research Focuses \\
\hline \multirow{3}{*}{$\begin{array}{l}\text { Estimating LAI and } \\
\text { biomass }\end{array}$} & Xie et al. [109] & $\begin{array}{c}\text { Evaluated a range of vegetation indices, such as the modified } \\
\text { simple ratio index (MSR), NDVI, a newly proposed index } \\
\text { NDVI-like (which resembles NDVI), modified triangular } \\
\text { vegetation index (MTVI2), and modified soil adjusted vegetation } \\
\text { index (MSAVI) for estimating winter wheat LAI from } \\
\text { hyperspectral images. }\end{array}$ \\
\hline & Ambrus et al. [104] & $\begin{array}{l}\text { Tested the NDVI and Red Edge Position (REP) for estimating } \\
\text { field-scale winter wheat biomass. }\end{array}$ \\
\hline & Richter et al. [98] & $\begin{array}{l}\text { Examined a range of techniques (e.g., index-based empirical } \\
\text { regression, radiative transfer modelling, and artificial neural } \\
\text { network) for estimating crop biophysical variables (e.g., LAI and } \\
\text { water content) in terms of operational agricultural applications } \\
\text { with airborne Hymap data and discussed the unique features of } \\
\text { each technique. }\end{array}$ \\
\hline $\begin{array}{l}\text { Estimating nitrogen } \\
\text { content }\end{array}$ & Nevalainen et al. [163] & $\begin{array}{c}\text { Utilized } 28 \text { published vegetation indices (e.g., Chlorophyll } \\
\text { Absorption Ratio Index (CARI) and Normalized Difference Red } \\
\text { Edge (NDRE)) for estimating oat nitrogen and identified the } \\
\text { best-performing one. }\end{array}$ \\
\hline \multirow[t]{2}{*}{$\begin{array}{l}\text { Detecting crop } \\
\text { disease }\end{array}$} & Huang et al. [164] & $\begin{array}{l}\text { Examined the performance of the photochemical reflectance } \\
\text { index (PRI) for estimating the disease index of wheat yellow rust } \\
\text { using canopy reflectance data and then applied the regression } \\
\text { on an airborne hyperspectral imagery for mapping the } \\
\text { disease-affected areas. }\end{array}$ \\
\hline & Copenhaver et al. [34] & $\begin{array}{c}\text { Calculated a range of vegetation indices (e.g., NDVI and red } \\
\text { edge position index) for detecting crop disease and compared } \\
\text { the effectiveness of these indices. }\end{array}$ \\
\hline $\begin{array}{l}\text { Estimating crop } \\
\text { residue cover }\end{array}$ & Galloza and Crawford [47] & $\begin{array}{l}\text { Utilized the Normalized Difference Tillage Index (NDTI) and } \\
\text { Cellulose Absorption Index (CAI), together with ALI, Hyperion, } \\
\text { and airborne hyperspectral (SpecTIR) data, for estimating crop } \\
\text { residue cover for conservation tillage application. }\end{array}$ \\
\hline Crop classification & Thenkabail et al. [44] & $\begin{array}{c}\text { Utilized both spectral bands and vegetation indices for } \\
\text { classifying different crop types and estimating vegetation } \\
\text { properties and evaluated the performance difference of using } \\
\text { various bands or indices. }\end{array}$ \\
\hline
\end{tabular}

Overall, linear regression has been commonly used for estimating a wide range of crop or soil properties. It is easy to establish, and most of the index-based regressions generated satisfactory accuracies. However, there are several potential issues associated with this approach, such as the large number of indices available and it is unknown which performs better, regression may be very sensitive to data size and quality, and the saturation problem of indices [36,165]. It is thus critical to consider these potential issues and adopt appropriate solutions when establishing linear regressions with hyperspectral data. For instance, selecting appropriate vegetation indices with targeted crop or soil variables is recommended. Researchers have evaluated a wide range of hyperspectral vegetation indices for different research purposes. Haboudane et al. [166] examined 11 hyperspectral vegetation indices for estimating crop chlorophyll content. Main et al. [167] investigated 73 vegetation indices for estimating chlorophyll content in crop and savanna tree species. Peng and Gitelson [168] tested 10 multispectral indices and 4 hyperspectral indices for quantifying crop gross primary productivity. Croft et al. [169] analyzed 47 hyperspectral indices for estimating the leaf chlorophyll content of different tree species. Zhou et al. [170] evaluated eight hyperspectral indices for estimating the canopy-level wheat nitrogen content. Tong and He [165] evaluated 21 multispectral and 123 hyperspectral vegetation indices for calculating the grass chlorophyll content at both the leaf and canopy scales. Yue et al. [171] examined 54 hyperspectral vegetation indices for estimating winter wheat biomass. Indices performed differently 
in these studies; thus, it is suggested to evaluate the top-performed ones in these studies and select the one that generates the highest accuracy.

To deal with issues of linear regression, advanced regression, such as MLR and PLSR, has also been commonly used in previous research for estimating crop and soil properties [172,173]. Compared with linear regression, the advanced regression models mostly use multiple predictor variables in the model to achieve a higher accuracy. PLSR is one of the most widely used models for investigating crop properties using hyperspectral images, such as Ryu et al. [35], Jarmer [99], Siegmann et al. [73], and Yue et al. [124] used PLSR and hyperspectral images for estimating different crop biophysical and biochemical variables (e.g., LAI, biomass, chlorophyll, content, fresh matter, and nitrogen contents). Thomas et al. [100] examined PLSR for retrieving the biogas potential from hyperspectral images and evaluated the influence of imaging time on retrieval accuracy. Regarding soil features, Gomez et al. [49], Van Wesemael et al. [107], Hbirkou et al. [102], and Castaldi et al. [110] built a PLSR model for estimating the SOC content using hyperspectral images. Zhang et al. [50] used PLSR for estimating a wide range of soil properties (e.g., soil moisture, soil organic matter, clay, total carbon, phosphorus, and nitrogen content) from hyperspectral imagery and identified factors that may affect the model accuracy (e.g., low signal-to-noise ratio, spectral overlap of different soil features). Casa et al. [59] used the PLSR model and different hyperspectral imagery for investigating soil textural features and evaluated various factors (e.g., spectral range and resolution, soil moisture, geolocation error) influencing the model performance.

The PLSR model is implemented in Python and R [174,175] and is widely used in many research areas, including forests [176], grasslands [177], and waters [178]. This model performed well in different studies owning to its strengths in dealing with a large number of inter-correlated predictor variables (i.e., by converting them to a few non-correlated latent variables), addressing the data noise challenge, and tackling the over-fitting problem $[171,179]$. Different techniques have also been confirmed to be efficient for improving the accuracy of the PLSR model, such as incorporating different types of predictor variables in the model (e.g., spectral bands, indices, textural variables), utilizing predicted residual error sum of squares (PRESS) statistics for determining the optimal number of latent variables, and feature evaluation for selecting more important predictor variables in the model [36]. It is thus critical to carefully examine these techniques for achieving the optimal model accuracy.

\subsection{Radiative Transfer Modelling}

Radiative transfer modelling is a physically based approach that uses physical laws to simulate the interaction of electromagnetic radiation with vegetation (e.g., reflection, transmission, and absorption) [180]. The RTMs simulate vegetation spectra (e.g., leaf reflectance and transmittance) using vegetation biophysical and biochemical properties (e.g., chlorophyll and water contents) in the forward mode, and for inversion of these variables from spectral measurements in the inverse mode [181]. PROSAIL is one of the most widely used RTMs. This model is an integration of the leaf-level PROSPECT model and canopy-level SAIL model and is capable of simulating canopy reflectance using leaf properties (e.g., chlorophyll and water contents), canopy structural parameters (e.g., LAI and leaf angle), and soil reflectance [18].

PROSAIL has also been used in agricultural environments for investigating crop and soil properties. For instance, Casa and Jones [182] inverted PROSAIL and a ray-tracing canopy model with spectroradiometer-measured hyperspectral reflectance data and imaging spectrometer-acquired hyperspectral image data, respectively, for estimating canopy LAI and evaluated factors influencing the estimation accuracy (e.g., the non-homogeneous surface caused by the crop row structure). Richter et al. [98] utilized PROSAIL for estimating LAI, fCover, canopy chlorophyll, and water content from hyperspectral images and compared its performance to other methods (e.g., artificial neural network). Richter et al. [183] applied PROSAIL to investigate similar vegetation variables and analyzed the accuracy and efficiency of this method. Wu et al. [184] examined the sensitivity of vegetation indices to vegetation chlorophyll content using simulated results from the PROSPECT model and suggested 
a few well-performed indices. Locherer et al. [74] attempted to estimate vegetation LAI using the PROSAIL model and multi-source hyperspectral images and tested several techniques (e.g., different cost functions and types of averaging methods) used for the inversion process. Yu et al. [37] estimated a range of vegetation phenotyping variables (e.g., LAI and leaf chlorophyll) using hyperspectral imagery and PROSAIL and examined the sensitivity of different spectral ranges to the parameters in the PROSAIL model.

Compared with the regression models discussed in previous sections, the RTMs have been less used in the literature for investigating agricultural features due mainly to their high model complexity and computational intensity. For instance, a wide range of parameters need to be considered in RTM (e.g., chlorophyll, carotenoids, water contents, leaf area index, leaf angles, solar angles, and soil reflectance, along with other parameters, in the PROSAIL model) and the users need to use different techniques (e.g., merit function, look-up table) to facilitate the forward and inversion operations of the model. In addition, it costs much more computing time than the regression models to achieve the predictions of target vegetation variables. However, it is also well known that the regression models tend to be site and time specific and are not readily transferable to other geographical regions or different times over the site [166]. In contrast, RTM is a more transferable approach owning to the fact that it is established based on physical laws and does not require training data for rebuilding the model. In addition, RTM is capable of estimating a range of vegetation properties in one model, while regression models typically can only estimate one variable $[36,185]$.

\subsection{Machine Learning and Deep Learning}

Machine learning algorithms, including support vector machine regression (SVM) and RF, are powerful tools for analyzing hyperspectral information since they can process a large number of variables (e.g., spectral reflectance and vegetation indices) efficiently [186]. Machine learning has been widely used in the remote sensing field for estimating properties of ground features or classifying different ground covers $[36,114,187]$. Researchers have also used different machine learning algorithms and hyperspectral images for agricultural applications. SVM has been a commonly used algorithm in previous research for prediction or classification purposes. For instance, Honkavaara et al. [123] estimated crop biomass using SVM and UAV-acquired hyperspectral imagery. Bostan et al. [51] utilized SVM for classifying different crop types and achieved high classification accuracy. Ran et al. [93] used KNN and SVM classifiers for investigating tillage practices in agricultural fields and compared their performances. RF is another commonly used algorithm for investigating agricultural features with hyperspectral imagery. For instance, Gao et al. [188] successfully classified weed and maize using RF and lab-based hyperspectral images. Using ground-based hyperspectral reflectance data acquired by an ASD spectroradiometer, Siegmann and Jarmer [189] evaluated the performance of RF, SVM, and PLSR for estimating crop LAI and confirmed the good performance of RF. Similarly, using hyperspectral reflectance, Adam et al. [190] attempted to detect maize disease with the RF model. Overall, machine learning models generally have robust performances for investigating agricultural features using hyperspectral imagery.

Deep learning is a subset of machine learning and extends machine learning by adding more "depth" (i.e., hierarchical representation of the dataset) in the model [191,192]. It is a popular approach in recent years for recognizing patterns in remote sensing images and thus for investigating various ground features. Deep learning has been commonly used in the remote sensing field for image classification, such as land cover classification [193-195] and the identification of ground features (e.g., buildings) [196]. Deep learning has also been applied to precision farming to solve complicated issues. Existing studies are, for example, investigating the estimation of crop yield using CNN and multispectral images together with climate data [197], plant disease detection using CNN and smartphone-acquired images [198], crop classification using 3-D CNN and multi-temporal multispectral images [199], and classification of agricultural land cover using deep recurrent neural network and multi-temporal SAR images [200]. Kamilaris and Prenafeta-Boldú [191] reviewed applications of deep 
learning in agriculture and food production, although not all studies used remote sensing images. Singh et al. [201] reviewed a range of deep learning methods and their applications, specifically in plant phenotyping. Up to now, deep learning has not been well explored for processing and analyzing remote sensing images, especially hyperspectral images, for agricultural applications. Considering the capacity of deep learning for studying feature patterns in images and the rich information in hyperspectral imagery, the integration of the two has a wide range of agricultural applications (e.g., crop classification, weed monitoring, crop disease detection, and plant stress evaluation). Further research in these areas is warranted.

Machine learning or deep learning is capable of processing multi-source and multi-type data [202]. For instance, besides multi-type remote sensing images (e.g., optical, thermal, LiDAR, and Radar), other sources of data, such as weather, irrigation, and historical yield information, can also be incorporated in the modelling process for a possibly better evaluation of targeted agricultural features [203]. Although machine learning and deep learning models are powerful, it is also critical to keep in mind that these models require large-quantity and high-quality training samples to achieve robust performances [202]. Insufficient training datasets or data with issues (e.g., data incompleteness, noise, and biases) may cause undesired model performances.

In summary, different analytical methods (e.g., linear regression, advanced regression, machine learning and deep learning, and RTM) have different levels of complexity, performance, and transferability. More detailed comparisons on these methods are listed in Table 7. Overall, linear regression is the easiest method to use, and its performance is generally acceptable, although this method can be highly influenced by the choice of predictor variables and quality of the sample data. The advanced regression (e.g., PLSR) mostly performs better than the linear regression since it involves multiple variables in the model and is less sensitive to data noise. RTM (e.g., PROSAIL) is capable of producing multiple data products (e.g., chlorophyll, water, and LAI) with reasonably high accuracies. One essential advantage of this method is its high transferability. However, this method has the highest complexity as it requires a wide range of parameters and extensive programming. In terms of machine learning, many algorithms, such as RF and SVM, are well established and mostly performed well in previous studies. Some programming and model adjustments are needed for this method to achieve optimal performance. Deep learning is a relatively new method and is increasingly popular in recent years. Appropriate model design and programming are critical for this approach. It also requires a substantial amount of training data and computing resources to achieve a good model performance. 
Table 7. Comparison of different analytical methods.

\begin{tabular}{|c|c|c|c|c|c|}
\hline Methods & Linear Regression & Advanced Regression & $\begin{array}{l}\text { Radiative Transfer } \\
\text { Modelling }\end{array}$ & Machine Learning & Deep Learning \\
\hline $\begin{array}{l}\text { Parameters typically used } \\
\text { in the model }\end{array}$ & $\begin{array}{l}\text { - One predictor } \\
\text { variable (e.g., } \\
\text { reflectance or } \\
\text { vegetation index) } \\
\text { - Response variable } \\
\text { (e.g., chlorophyll) }\end{array}$ & $\begin{array}{l}\text { - Multiple } \\
\text { predictor variables } \\
\text { - Response variable } \\
\text { - Parameters in the model } \\
\text { (e.g., the number of } \\
\text { latent variables in PLSR) }\end{array}$ & $\begin{array}{l}\text { - A wide range of } \\
\text { predictor variables (e.g., } \\
\text { leaf biophysical and } \\
\text { biochemical properties) } \\
\text { - Parameters in the model } \\
\text { (e.g., absorption } \\
\text { coefficients, the } \\
\text { refractive index of leaf } \\
\text { material in PROSAIL) }\end{array}$ & $\begin{array}{l}\text { - Multiple } \\
\text { predictor variables } \\
\text { - Response variable } \\
\text { - Parameters in the } \\
\text { model (e.g., number } \\
\text { of trees in the } \\
\text { RF model) }\end{array}$ & $\begin{array}{l}\text { - Predictor variables } \\
\text { as input layers } \\
\text { - Sizes and weights } \\
\text { of layers } \\
\text { - Number of layers } \\
\text { for calculating }\end{array}$ \\
\hline Model complexity & Low & Medium & High & Medium & High \\
\hline Model performance & $\begin{array}{l}\text { Low-high } \\
\text { (depend on predictor } \\
\text { variable used) }\end{array}$ & Medium—high & Medium—high & Medium—high & Medium—high \\
\hline $\begin{array}{l}\text { Transferability in time and } \\
\text { geographical location }\end{array}$ & Low & Low & High & Low & High \\
\hline $\begin{array}{l}\text { Typical agricultural } \\
\text { applications }\end{array}$ & \multicolumn{3}{|c|}{ Prediction of agricultural variables (e.g., yield, LAI) } & \multicolumn{2}{|c|}{$\begin{array}{l}\text { Prediction of agricultural variables } \\
\text { Classification of agricultural features }\end{array}$} \\
\hline $\begin{array}{l}\text { Application } \\
\text { recommendations }\end{array}$ & $\begin{array}{l}\text { - Test a range of } \\
\text { predictor variables } \\
\text { and identify the best } \\
\text { performed one } \\
\text { - Check data noise in } \\
\text { the training samples }\end{array}$ & $\begin{array}{l}\text { - Involve different types } \\
\text { of variables (e.g., } \\
\text { spectral and textural) } \\
\text { - Check contributions of } \\
\text { variables to the model } \\
\text { - Tuning model } \\
\text { parameters to achieve } \\
\text { optimal performance }\end{array}$ & $\begin{array}{l}\text { - Collect a set of } \\
\text { vegetation biophysical } \\
\text { and } \\
\text { biochemical parameters } \\
\text { - Adjust the model to } \\
\text { improve } \\
\text { calculating efficiency }\end{array}$ & $\begin{array}{l}\text { - Involve different } \\
\text { types of variables } \\
\text { (e.g., spectral } \\
\text { and textural) } \\
\text { - Tuning model } \\
\text { parameters to } \\
\text { achieve } \\
\text { optimal performance }\end{array}$ & $\begin{array}{l}\text { - Optimize } \\
\text { model configurations } \\
\text { - Large size of } \\
\text { training samples }\end{array}$ \\
\hline
\end{tabular}




\section{Hyperspectral Applications in Agriculture}

Hyperspectral imaging has been used in agriculture for a wide range of purposes, including estimating crop biochemical properties (e.g., chlorophyll, carotenoids, and water contents) and biophysical properties (e.g., LAI, biomass) for understanding vegetation physiological status and predicting yield, evaluating crop nutrient status (e.g., nitrogen deficiency), monitoring crop disease, and investigating soil properties (e.g., soil moisture, soil organic matter, and soil carbon). Previous studies have also summarized some of the above-mentioned applications of hyperspectral remote sensing in precision agriculture $[4,84]$. In this section, we will thus focus more on recent hyperspectral studies and summarize these studies according to specific applications.

\subsection{Estimation of Crop Biochemical and Biophysical Properties}

One important hyperspectral application in agriculture is monitoring crop conditions through the retrieval of crop biochemical and biophysical properties $[8,99]$. For instance, the leaf chlorophyll content is an essential biochemical property influencing the vegetation photosynthetic capacity and controlling crop productivity [99]. In previous studies, Oppelt and Mauser [105] collected AVIS data to retrieve the chlorophyll and nitrogen contents in a winter wheat field. Similarly, Moharana and Dutta [43] used Hyperion data to estimate the contents of these two biochemical components in a rice field. LAI, on the other hand, is a fundamental vegetation biophysical parameter and is highly related to crop biomass and yield [98]. Previous studies have used hyperspectral remote sensing to estimate the LAI of different crops, and some of the example studies are shown in Table 8.

Table 8. Selected previous studies estimating LAI for different crop types using hyperspectral images.

\begin{tabular}{|c|c|c|}
\hline Crops & Previous Studies & Research Focuses \\
\hline \multirow{2}{*}{ Winter wheat } & Xie et al. [109] & $\begin{array}{l}\text { Estimated canopy LAI in a winter wheat field using airborne } \\
\text { hyperspectral imagery and proposed a new vegetation index for } \\
\text { improved estimation accuracy. }\end{array}$ \\
\hline & Siegmann et al. [73] & $\begin{array}{l}\text { Retrieved LAI of two wheat fields using EnMAP images and } \\
\text { attempted to pan-sharp the images aiming to improve the } \\
\text { spatial resolution of LAI products. }\end{array}$ \\
\hline Barley & Jarmer [99] & $\begin{array}{l}\text { Retrieved a range of canopy variables from barley, including } \\
\text { LAI, chlorophyll, water, and fresh matter content using HyMap } \\
\text { data and established an efficient approach for monitoring the } \\
\text { spatial patterns of crop variables. }\end{array}$ \\
\hline Rice & Yu et al. [37] & $\begin{array}{l}\text { Investigated LAI, leaf chlorophyll content, canopy water } \\
\text { content, and dry matter content using UAV-based hyperspectral } \\
\text { imagery, aiming to understand the growing status of rice. }\end{array}$ \\
\hline \multirow{4}{*}{$\begin{array}{l}\text { Mixed } \\
\text { agricultural } \\
\text { fields }\end{array}$} & Richter et al. [98] & $\begin{array}{l}\text { Estimated crop LAI and water content with airborne HyMap } \\
\text { data aiming to support operational agricultural practices (e.g., } \\
\text { irrigation management and crop stress detection) in the context } \\
\text { of the EnMap hyperspectral mission. }\end{array}$ \\
\hline & Wu et al. [45] & $\begin{array}{l}\text { Estimated chlorophyll content and LAI in a mixed agricultural } \\
\text { field (e.g., corns, chestnuts trees, and tea plants) using Hyperion } \\
\text { data and identified spectral bands and vegetation indices that } \\
\text { generated the highest accuracy. }\end{array}$ \\
\hline & Verger et al. [57] & $\begin{array}{l}\text { Estimated LAI, fCover, and FAPAR in an agricultural site with } \\
\text { different crops using PROBA-CHRIS data. }\end{array}$ \\
\hline & Locherer et al. [74] & $\begin{array}{l}\text { Estimated LAI in mixed crop fields using EnMAP data and } \\
\text { compared the result accuracy to that of LAI estimation with } \\
\text { airborne data. }\end{array}$ \\
\hline
\end{tabular}


In addition to the above-mentioned vegetation biochemical and biophysical properties, crop water content is a critical parameter for revealing water stress. Richter et al. [98] attempted to estimate the water content in maize, sugar beet, and winter wheat using airborne HyMap data. Moharana and Dutta [204] investigated the water stress in a rice field and its variations using Hyperion images and indicated that the remote sensing-estimated water content matched well with field-observed data. Izzo et al. [128] evaluated the water status in a commercial vineyard using UAV-based hyperspectral data and determined wavelengths sensitive to the canopy water content. Sahoo et al. [4] discussed the applications of hyperspectral remote sensing data for evaluating water features in crops and listed several vegetation indices for calculating the water content.

It can be found from the literature review that many previous studies have focused on estimating the crop chlorophyll content, LAI, and water content using hyperspectral imagery, while other important crop properties, such as carotenoids, that are sensitive to plant stress are less explored. In addition, crop production is influenced by all of these vegetation properties (e.g., chlorophyll, water, and LAI). Besides investigating the spatial and temporal variations of each property, it is also critical to evaluate the relationships between these properties and further understand how they affect crop growth and crop production.

Estimating crop biomass and forecasting yield are also important applications of remote sensing, as they will contribute to the understanding of crop productivity and implementing suitable management measures [126]. Yue et al. [124] utilized UAV-based hyperspectral images for estimating the above-ground biomass of winter wheat. Yang [205] and Mariotto et al. [15] utilized both multispectral and hyperspectral data to estimate crop yield and found that the hyperspectral imagery-based model performed better. In addition, crop residues left in the field are critical materials protecting soil from water and wind erosion and influencing soil biochemical processes. Previous studies, such as Bannari et al. [106], Galloza and Crawford [47], Bannari et al. [46], have used different hyperspectral images for the estimation of crop residues on farmlands

Beyond the estimation of crop biomass and residue, one further research topic is investigating bioenergy (e.g., biogas), which can be generated from the crop biomass. Thomas et al. [100] attempted to estimate the amount of biogas that can be generated per unit of biomass using airborne HyMap data and achieved satisfactory results. Overall, hyperspectral imagery has contributed greatly to the estimation of crop biomass, yield, and other related features (e.g., bioenergy, crop residues). Since crop biomass and yield are highly affected by agricultural practices (e.g., watering and nutrition treatment), involving these practice data, together with hyperspectral imagery, in the model can potentially generate better results. More research in this area is warranted.

\subsection{Evaluating Crop Nutrient Status}

Precision farming involves evaluating the crop nutrient status and providing recommendations on site-specific resource management according to crop needs [206]. Such an approach is critical for improving the resource use efficiency and reducing environmental impacts $[4,103]$. Previous studies have used hyperspectral images for estimating the nitrogen content of different crop types, as shown in Table 9.

Table 9. Selected previous studies estimating the nitrogen content for different crop types using hyperspectral images.

\begin{tabular}{ccr}
\hline Crop types & Previous Studies & Research Focuses \\
\hline Corn & Akhtman et al. [127] & $\begin{array}{r}\text { Used UAV-based hyperspectral images for estimating nitrogen } \\
\text { content and phytomass in corn and wheat fields and monitored the } \\
\text { temporal variation of these properties. }\end{array}$ \\
\cline { 2 - 3 } & Goel et al. [207] & $\begin{array}{r}\text { Collected hyperspectral images in a cornfield with different nitrogen } \\
\text { treatments and weed controls aiming to evaluate to what extent the } \\
\text { spectral signals can identify different nitrogen treatments, weed } \\
\text { controls, or their interactions. }\end{array}$ \\
\hline
\end{tabular}


Table 9. Cont.

\begin{tabular}{lc}
\hline Crop types & Previous Studies \\
& Research Focuses \\
Cilia et al. [103] & $\begin{array}{c}\text { Estimated nitrogen concentration and dry mass in an experimental } \\
\text { maize field using airborne hyperspectral imagery, aiming to } \\
\text { map. The authors also suggested a way to evaluate the minimum } \\
\text { amount of nitrogen to apply without reducing crop yield and avoid } \\
\text { excessive fertilization. }\end{array}$
\end{tabular}

Quemada et al. [208]

Evaluated plant nitrogen status in a maize field using airborne hyperspectral images and developed nitrogen fertilizer recommendations.

\begin{tabular}{|c|c|c|}
\hline \multirow{3}{*}{ Wheat } & Koppe et al. [209] & $\begin{array}{l}\text { Attempted to investigate wheat nitrogen status and aboveground } \\
\text { biomass using hyperspectral and radar images and to evaluate } \\
\text { spectral signatures of wheats under different nitrogen treatments. }\end{array}$ \\
\hline & Kaivosoja et al. [126] & $\begin{array}{l}\text { Used UAV-based hyperspectral imagery to investigate nitrogen } \\
\text { content and absolute biomass in a wheat field and evaluated the } \\
\text { degree of nitrogen shortage on the date of image acquisition. In this } \\
\text { research, historical farming data, including a yield map and a spring } \\
\text { fertilization map, were used for estimating the optimal amount of } \\
\text { fertilizer to be applied in different areas of the field. }\end{array}$ \\
\hline & Castaldi et al. [210] & $\begin{array}{c}\text { Estimated nitrogen content in wheat using multi-temporal } \\
\text { satellite-based multispectral and hyperspectral images and found } \\
\text { that the band selection affected estimation accuracy at different } \\
\text { phenological stages. }\end{array}$ \\
\hline \multirow{4}{*}{ Rice } & Moharana and Dutta [43] & $\begin{array}{l}\text { Collected Hyperion images for monitoring nitrogen and chlorophyll } \\
\text { contents in rice and investigated the performance of different } \\
\text { spectral indices. }\end{array}$ \\
\hline & Ryu et al. [35] & $\begin{array}{l}\text { Used airborne hyperspectral images and multivariable analysis to } \\
\text { estimate nitrogen content in rice at the heading stage. }\end{array}$ \\
\hline & Zheng et al. [211] & $\begin{array}{l}\text { Tried to monitor rice nitrogen status using UAV-based hyperspectral } \\
\text { images and tested the performance of different vegetation indices } \\
\text { for estimating the nitrogen content. }\end{array}$ \\
\hline & Zhou et al. [212] & $\begin{array}{l}\text { Estimated leaf nitrogen concentration of rice using close-range } \\
\text { hyperspectral images and tested if the variations of the spatial } \\
\text { resolution of the imagery affect the estimation accuracy. }\end{array}$ \\
\hline \multirow{6}{*}{$\begin{array}{l}\text { Other crops } \\
\text { (i.e., barley, } \\
\text { potato, } \\
\text { cabbage, } \\
\text { tomato, } \\
\text { sugarcane, } \\
\text { and cacao) }\end{array}$} & Nasi et al. [213] & $\begin{array}{l}\text { Evaluated the performance of using airborne hyperspectral images } \\
\text { and photogrammetric features for estimating crop nitrogen content } \\
\text { and biomass in a barley field and a grassland site, and examined if } \\
\text { the integration of spectral and plant height information can improve } \\
\text { the estimation results. }\end{array}$ \\
\hline & Nigon et al. [214] & $\begin{array}{l}\text { Examined nitrogen stress in potato fields using airborne } \\
\text { hyperspectral imagery and identified spectral indices that are } \\
\text { sensitive to nitrogen content. }\end{array}$ \\
\hline & Chen et al. [215] & $\begin{array}{l}\text { Estimated nitrogen content in cabbage seedlings using close-range } \\
\text { hyperspectral images and identified sensitive wavelengths for the } \\
\text { estimation. }\end{array}$ \\
\hline & Zhu et al. [142] & $\begin{array}{l}\text { Investigated soluble sugar, total nitrogen, and their ratio in tomato } \\
\text { leaves using close-range hyperspectral images and tested data } \\
\text { fusion analysis techniques for improving the investigation accuracy. }\end{array}$ \\
\hline & $\begin{array}{l}\text { Miphokasap and } \\
\text { Wannasiri [216] }\end{array}$ & $\begin{array}{l}\text { Collected Hyperion images for investigating spatial variations of } \\
\text { sugarcane canopy nitrogen concentration and attempted to identify } \\
\text { the nutrient deficient areas for corresponding treatments. }\end{array}$ \\
\hline & Malmir et al. [217] & $\begin{array}{l}\text { Attempted to evaluate nutrient status (e.g., nitrogen, phosphorus, } \\
\text { and potassium) of cacao leaves using close-range hyperspectral } \\
\text { images and examined influences of band selection on the evaluation } \\
\text { accuracy. }\end{array}$ \\
\hline
\end{tabular}


Overall, owing to the large amount of spectral information in hyperspectral imagery, crop nutrient status can be evaluated with high accuracies, and a corresponding fertilizer treatment plan can be proposed to achieve optimal crop productions. However, it is also essential to keep in mind that there is a wide range of factors, such as soil moisture, soil type, and topographic conditions, that can impact crop growth and production. A more comprehensive treatment plan that takes into consideration both the crop nutrient status and other influencing factors can make a greater contribution to crop production.

\subsection{Classifying Imagery to Identify Crop Types, Growing Stages, Weeds/Invasive Species, and Stress/Disease}

Besides quantifying crop properties, hyperspectral images have also been used for classification purposes, such as differentiating crop types, identifying crop growing stages, classifying weeds or invasive species, and detecting disease [218]. Examples of previous studies are shown in Table 10. Different agricultural land covers or crop types have different spectral characteristics; hence, hyperspectral images can contribute greatly to the classification of these agricultural features.

Table 10. Selected previous studies for the classification of agricultural features using hyperspectral images.

\begin{tabular}{|c|c|c|}
\hline Applications & Previous Studies & Research Focuses \\
\hline \multirow{5}{*}{$\begin{array}{l}\text { Classification of } \\
\text { crop types }\end{array}$} & Camacho Velasco et al. [48] & $\begin{array}{c}\text { Utilized Hyperion data and different classification algorithms } \\
\text { (e.g., spectral angle mapper and adaptive coherence estimator) } \\
\text { for identifying five types of crops (e.g., oil palm, rubber, grass } \\
\text { for grazing, citrus, and sugar cane) in Colombia. }\end{array}$ \\
\hline & Bostan et al. [51] & $\begin{array}{l}\text { Classified different crop and land cover types (e.g., maize, } \\
\text { cotton, urban, water, barren rock, and other crop types) using } \\
\text { Landsat } 8 \text { multispectral and EO-1 Hyperion hyperspectral } \\
\text { images and indicated that hyperspectral imagery performed } \\
\text { better than the multispectral imagery. }\end{array}$ \\
\hline & Amato et al. [152] & $\begin{array}{l}\text { Assessed the potential of PRISMA data for classifying different } \\
\text { agricultural land uses (e.g., soybean, corn, and sugar beet) and } \\
\text { evaluated the contribution of spectral bands to image } \\
\text { segmentation and classification. }\end{array}$ \\
\hline & Nigam et al. [91] & $\begin{array}{l}\text { Performed crop classification over homogeneous and } \\
\text { heterogeneous agriculture and horticulture areas with airborne } \\
\text { AVIRIS images and assessed crop health at the field scale. }\end{array}$ \\
\hline & Sahoo et al. [4] & $\begin{array}{c}\text { Reviewed a few previous studies that used hyperspectral } \\
\text { images for classification purposes and indicated the robustness } \\
\text { of hyperspectral imagery for classifying different crop types and } \\
\text { different crop phonological stages. }\end{array}$ \\
\hline \multirow{3}{*}{$\begin{array}{l}\text { Other } \\
\text { classifications } \\
\text { (e.g., growth stages } \\
\text { and agricultural } \\
\text { tillage practices) }\end{array}$} & Antony et al. [58] & $\begin{array}{c}\text { Applied multi-angle PROBA-CHRIS data for classifying } \\
\text { different growth stages of wheat. }\end{array}$ \\
\hline & Ran et al. [93] & $\begin{array}{l}\text { Attempted to detect agricultural tillage practices using } \\
\text { hyperspectral imagery with different classification models and } \\
\text { identified the best performing one. }\end{array}$ \\
\hline & Teke et al. [38] & $\begin{array}{l}\text { Discussed the application of spectral libraries for classification } \\
\text { purposes and listed several spectral libraries available } \\
\text { worldwide. The authors also indicated the limitations of using a } \\
\text { spectral library, such as the spectral varieties within the same } \\
\text { species or land cover, and highlighted the importance of having } \\
\text { geographically specific libraries }\end{array}$ \\
\hline
\end{tabular}

Weed infestation is a severe issue in agricultural fields and could substantially affect crop growth and yield. Identifying and mapping weeds in agricultural fields using remote sensing will contribute greatly to variable rate treatment in the fields [219]. Researchers have utilized different remote sensing data and methods for weed mapping, as shown in Table 11. Overall, the identification of weeds typically requires a high spatial resolution since many weeds are small in size and mixed with crops. 
UAV-based and close-range hyperspectral imaging is capable of acquiring high-spatial-resolution images, and thus has high potential to contribute to weed detection.

Table 11. Selected previous studies for detecting weeds using different hyperspectral imaging platforms.

\begin{tabular}{|c|c|c|}
\hline Platforms & Previous Studies & Research Focuses \\
\hline \multirow{2}{*}{ Airborne } & Goel et al. [97] & $\begin{array}{l}\text { Attempted to detect weed infestation in a cornfield that } \\
\text { had different nitrogen treatments using airborne } \\
\text { hyperspectral imagery and found the different nitrogen } \\
\text { treatments affected the classification accuracy of weed. }\end{array}$ \\
\hline & Karimi et al. [220] & $\begin{array}{c}\text { Performed combinations of different nitrogen treatment } \\
\text { rates and weed management practices in a cornfield and } \\
\text { tried to classify these combinations with airborne } \\
\text { hyperspectral images. }\end{array}$ \\
\hline \multirow{4}{*}{ Close range } & Zhang et al. [221] & $\begin{array}{l}\text { Developed a close-range weed sensing system using } \\
\text { hyperspectral images for classifying tomato and weeds } \\
\text { and tested its performance in different environments. }\end{array}$ \\
\hline & Eddy et al. [139] & $\begin{array}{c}\text { Used a ground-based hyperspectral imaging system for } \\
\text { classifying weeds in canola, pea, and wheat crops and } \\
\text { evaluated the applicability of this approach for real-time } \\
\text { detection of weeds in the field. }\end{array}$ \\
\hline & Eddy et al. [222] & $\begin{array}{l}\text { Used hyperspectral image data as well as secondary } \\
\text { products with reduced bands to classify weeds and } \\
\text { achieved good accuracy. }\end{array}$ \\
\hline & Liu et al. [223] & $\begin{array}{c}\text { Classified carrot and weeds using a ground-based } \\
\text { hyperspectral imaging system and evaluated the number } \\
\text { of spectral bands needed to achieve a good classification } \\
\text { accuracy. }\end{array}$ \\
\hline Multiple platforms & Scherrer et al. [129] & $\begin{array}{l}\text { Attempted to classify herbicide-resistant weeds in } \\
\text { different crop fields (e.g., barley, corn, and dry pea) using } \\
\text { both ground- and UAV-based hyperspectral imagery and } \\
\text { discussed factors influencing classification accuracy (e.g., } \\
\text { crop type, plant age, and illumination condition). }\end{array}$ \\
\hline Review studies & LÓPEZ-Granados [224] & $\begin{array}{l}\text { Discussed the high potential of hyperspectral remote } \\
\text { sensing images for mapping weeds but also indicated } \\
\text { the limitations of this technology due to the high cost of } \\
\text { data collection. }\end{array}$ \\
\hline
\end{tabular}

Monitoring crop disease is highly important to growers trying to reduce economic and yield losses [38]. Hyperspectral imaging collects signals at fine spectral resolutions (e.g., less than 10-nm intervals), and thus can possibly detect early symptoms of crop disease and support timely interventions [225]. Previous studies have used hyperspectral images for detecting diseases in different types of groups (Table 12). Overall, hyperspectral signals are sensitive to the variations of crop growth status (e.g., caused by disease or stress) and thus can indicate the occurrence of crop disease or stress. However, considering that crop status can be affected by other factors (e.g., nutrient deficiency), repeat imaging and analysis together with robust modelling would be critical for accurate and timely detection of crop disease or stress. 
Table 12. Selected previous studies for detecting disease in different crops using hyperspectral images.

\begin{tabular}{|c|c|c|}
\hline Crops & Previous Studies & Research Focuses \\
\hline \multirow{3}{*}{ Wheat } & Bohnenkamp et al. [119] & $\begin{array}{l}\text { Used both ground- and UAV-based hyperspectral imaging } \\
\text { platforms for detecting yellow rust in wheat and evaluated } \\
\text { factors influencing the detection (e.g., measurement distance, } \\
\text { spectral features to use). }\end{array}$ \\
\hline & Bauriegel et al. [226] & $\begin{array}{l}\text { Targeted the infestation of wheat by Fusarium and attempted to } \\
\text { detect this disease using hyperspectral remote sensing data, and } \\
\text { consequently suggested that farmers need to deal with infected } \\
\text { crops separately from healthy crops. }\end{array}$ \\
\hline & Zhang et al. [227] & $\begin{array}{l}\text { Attempted to detect the Fusarium head blight in winter wheat } \\
\text { similarly using close-range hyperspectral imaging and } \\
\text { suggested that this is a stable and feasible way to monitor this } \\
\text { disease using low-altitude remote sensing. }\end{array}$ \\
\hline Corn & Copenhaver et al. [34] & $\begin{array}{c}\text { Used airborne hyperspectral images to detect the signal of } \\
\text { Ostrinia nubilalis in a cornfield (e.g., via monitoring rate of plant } \\
\text { senescence) and tested the performance of this approach } \\
\text { throughout the growing season. }\end{array}$ \\
\hline Soybean & Nagasubramanian et al. [144] & $\begin{array}{l}\text { Tried to detect charcoal rot in soybeans using close-range } \\
\text { hyperspectral imaging and identified wavelength ranges that } \\
\text { are sensitive to this disease. }\end{array}$ \\
\hline Sugarcane & Apan et al. [41] & $\begin{array}{l}\text { Detected sugarcane areas affected by orange rust disease using } \\
\text { Hyperion data and developed specific vegetation indices that } \\
\text { are sensitive to the disease. }\end{array}$ \\
\hline Mustard & Dutta et al. [42] & $\begin{array}{l}\text { Delineated mustard areas influenced by diseases using Hyperion } \\
\text { images and evaluated the performance of different indices. }\end{array}$ \\
\hline \multirow{3}{*}{$\begin{array}{l}\text { Review } \\
\text { studies }\end{array}$} & Lowe et al. [218] & $\begin{array}{l}\text { Focused on hyperspectral imaging and reviewed some of its } \\
\text { applications in detecting and classifying crop disease and stress. }\end{array}$ \\
\hline & Thomas et al. [225] & $\begin{array}{l}\text { Reviewed the contributions of hyperspectral imaging to the } \\
\text { detection of plant disease and discussed different factors (e.g., } \\
\text { light and wind) that may limit its wide applications. }\end{array}$ \\
\hline & Mahlein et al. [228] & $\begin{array}{l}\text { Reviewed previous studies using remote sensing for detecting } \\
\text { plant disease, but not limited to hyperspectral imaging. }\end{array}$ \\
\hline
\end{tabular}

\subsection{Retrieving Soil Moisture, Fertility, and Other Physical or Chemical Properties}

Agricultural soil properties, including soil moisture, soil organic matter, soil salinity, and roughness, are important factors influencing crop growth and final production [7]. Hyperspectral remote sensing can contribute greatly to the investigation of these factors. For instance, estimating soil moisture is one of the most popular research topics. Finn et al. [108] estimated soil moisture at three different depths using airborne hyperspectral images and linear regression and discussed the contributions and limitations of hyperspectral remote sensing for soil moisture studies. Casa et al. [229] investigated soil water, clay, and sand contents using a fusion of CHRIS-PROBA images and soil geophysical data. Shoshany et al. [7] summarized four main approaches for estimating soil moisture content: (1) Radar techniques; (2) radiation balance and surface temperature calculations; (3) reflectance in the visible, NIR, and SWIR ranges; and (4) integrative methods using multiple spectral ranges. Although soil moisture can be estimated using optical remote sensing data, it is often affected by the plant ground cover. Integrating multi-type remote sensing data, e.g., SAR and thermal data, can possibly generate more accurate estimates.

SOC is a critical component of soil fertility, which highly controls both the growth and yield of crops. Hyperspectral data provide fine spectral details that are critical for the estimation of SOC content. Previous studies have used hyperspectral images collected by different platforms for investigating SOC (Table 13). Overall, hyperspectral imagery has a high potential for the estimation of soil organic 
matter and carbon. However, similar to the evaluation of soil moisture, the investigation of soil organic matter and carbon can be highly influenced by vegetation cover. Therefore, collecting hyperspectral images in non-growing seasons could be a solution.

Table 13. Selected previous studies for estimating soil organic carbon using hyperspectral images acquired by different platforms.

\begin{tabular}{|c|c|c|}
\hline Platforms & Previous Studies & Research Focuses \\
\hline \multirow[t]{2}{*}{ Satellites } & Zhang et al. [50] & $\begin{array}{l}\text { Utilized EO-1 Hyperion images for estimating several soil } \\
\text { properties, including soil moisture, soil organic matter, total } \\
\text { carbon, total phosphorus, total nitrogen, and clay content. The } \\
\text { authors also found the influence of spectral resolution on the } \\
\text { performance of retrieval models. }\end{array}$ \\
\hline & Casa et al. [230] & $\begin{array}{l}\text { Assessed soil organic matter and soil texture at the field scale } \\
\text { using CHRIS-PROBA images and produced uniform soil zones } \\
\text { for supporting irrigation management. }\end{array}$ \\
\hline \multirow{4}{*}{ Airplanes } & Hbirkou et al. [102] & $\begin{array}{c}\text { Attempted to estimate SOC in agricultural fields using airborne } \\
\text { HyMap images and tested the influences of soil surface } \\
\text { conditions on the estimation, aiming to support soil } \\
\text { management in precision farming. }\end{array}$ \\
\hline & Gedminas and Martin [231] & $\begin{array}{l}\text { Tried to map soil organic matter using airborne hyperspectral } \\
\text { imagery in combination with topographic information extracted } \\
\text { from LiDAR image and evaluated the correlation between soil } \\
\text { organic matter and various spectral bands. }\end{array}$ \\
\hline & Castaldi et al. [110] & $\begin{array}{l}\text { Investigated the relationship between SOC in croplands and } \\
\text { spectral signals using a soil database and then estimated SOC in } \\
\text { their study sites using airborne hyperspectral imagery. With this } \\
\text { approach, the authors attempted to reduce the amount of new } \\
\text { data collection in the field or lab. }\end{array}$ \\
\hline & Van Wesemael et al. [107] & $\begin{array}{l}\text { Discussed the impacts of vegetation cover on soil and the } \\
\text { estimation of SOC from remote sensing data and attempted to } \\
\text { use spectral unmixing techniques to estimate the fraction of } \\
\text { vegetation cover and then estimate the soil carbon content using } \\
\text { the residue soil spectra. }\end{array}$ \\
\hline $\begin{array}{l}\text { Multiple } \\
\text { platforms }\end{array}$ & Gomez et al. [49] & $\begin{array}{l}\text { Estimated SOC using both lab-based hyperspectral reflectance } \\
\text { data and Hyperion image data and found that using the } \\
\text { lab-acquired reflectance data can generate more accurate results } \\
\text { than using the Hyperion data. At the same time, the Hyperion } \\
\text { data can generate a SOC map that matches field observations } \\
\text { and thus can also be used for prediction. }\end{array}$ \\
\hline
\end{tabular}

Hyperspectral remote sensing data have also been used for estimating other soil features, as shown in Table 14. It can be found from these studies that hyperspectral images can be used for studying a wide range of soil features. Different soil features influence the spectral signals in different bands and with different magnitudes, while some of these influences may be spectrally overlapped. Therefore, when investigating a specific soil feature, it is critical to collect a suitable number of soil samples with other soil features generally controlled. 
Table 14. Selected previous studies for investigating different soil features using hyperspectral images.

\begin{tabular}{ccc}
\hline Soil Features & Previous Studies & Research Focuses \\
\hline Soil texture & Casa et al. [59] & $\begin{array}{r}\text { Investigated soil texture using airborne MIVIS and spaceborne } \\
\text { PROBA-CHRIS hyperspectral images and discussed their } \\
\text { performance and limitation (e.g., lack of SWIR band). }\end{array}$ \\
\hline Soil nitrogen & Song et al. [232] & $\begin{array}{r}\text { Used airborne hyperspectral images for evaluating the impact of } \\
\text { soil nitrogen applications and variable-rate fertilization on winter } \\
\text { wheat growth. The authors also indicated that the variable-rate } \\
\text { fertilization in the field could reduce the growing difference of } \\
\text { winter wheat caused by the spatial variations of soil nitrogen. }\end{array}$ \\
\hline $\begin{array}{c}\text { Copper } \\
\text { concentration }\end{array}$ & Antonucci et al. [147] & $\begin{array}{r}\text { Attempted to estimate in soil using lab-based hyperspectral } \\
\text { measurement and achieved good accuracy. }\end{array}$ \\
\hline Potassium & Wang et al. [233] & $\begin{array}{r}\text { Evaluated potassium content in cinnamon soil using close-range } \\
\text { hyperspectral imaging aiming to better understand soil fertility and } \\
\text { indicated the good performance of this approach when the } \\
\text { potassium content is high (i.e., } \geq 100 \text { mg/kg). }\end{array}$ \\
\hline $\mathrm{CO}_{2}$ leaks & McCann et al. [234] & $\begin{array}{r}\text { Detected } \mathrm{CO}_{2} \text { leaks from the soil by monitoring vegetation stress } \\
\text { signals using multi-temporal hyperspectral images. }\end{array}$ \\
\hline
\end{tabular}

In summary, hyperspectral imaging has been successfully applied to a wide range of agricultural applications, as reviewed above, and summarized in Table 15. Future research directions are also suggested. 
Table 15. Hyperspectral applications in agriculture.

\begin{tabular}{|c|c|c|}
\hline & Previous Focuses & Suggested Future Research Directions \\
\hline Crop biochemical and biophysical properties & $\begin{array}{l}\text { - Leaf area index } \\
\text { - Chlorophyll content } \\
\text { - Water content } \\
\text { - Fraction of vegetation cover } \\
\text { - Fresh/dry biomass, crop residue } \\
\text { - Yield }\end{array}$ & $\begin{array}{l}\text { - Vegetation properties related to crop stress (e.g., carotenoids) } \\
\text { - Relationships between different properties and how they } \\
\text { affect crop growth }\end{array}$ \\
\hline Crop nutrient status & - Nitrogen content & $\begin{array}{l}\text { - Other nutrients (e.g., phosphorus, magnesium, and boron } \\
\text { etc.) that may limit crop growth } \\
\text { - Optimized treatment plan targeting different limiting factors }\end{array}$ \\
\hline Classification & $\begin{array}{l}\text { Classification of: } \\
\text { - Crop types } \\
\text { - Soil types } \\
\text { - Growing stages (i.e., crop phenological features) } \\
\text { Classification and detection of stressors: } \\
\text { - Weeds or invasive species } \\
\text { - Disease/stress affected areas }\end{array}$ & $\begin{array}{l}\text { - Improvement of classification methods (e.g., advanced } \\
\text { algorithms) for target features } \\
\text { - Fusion and application of multi-type and multi-temporal } \\
\text { remote sensing data } \\
\text { - Further exploration of UAV and close-range imaging for } \\
\text { better identification of fine-scale signals }\end{array}$ \\
\hline Soil properties & $\begin{array}{l}\text { - Soil moisture } \\
\text { - Soil organic matter } \\
\text { - Soil salinity } \\
\text { - Soil roughness }\end{array}$ & $\begin{array}{l}\text { - Separation of spectral signals from soil and vegetation for } \\
\text { better assessing soil features } \\
\text { - Fusion and application of multi-type remote sensing data to } \\
\text { capture different soil information } \\
\text { - Further exploration of close-range sensing for investigating } \\
\text { soil properties. }\end{array}$ \\
\hline Agro-ecosystem & - Less explored using hyperspectral image & $\begin{array}{l}\text { - Ecosystem services } \\
\text { - Biodiversity } \\
\text { - Adverse effects of agricultural practices on the environments }\end{array}$ \\
\hline
\end{tabular}




\section{Conclusions and Recommendations}

Hyperspectral imaging has great potential for applications in agriculture, particularly precision agriculture, owing to ample spectral information sensitive to different plant and soil biophysical and biochemical properties. Multiple platforms, including satellites, airplanes, UAVs, and close-range platforms, have become more widely available in recent years for collecting hyperspectral images with different spatial, temporal, and spectral resolutions. These platforms also have different strengths and limitations in terms of spatial coverage, flight endurance, flexibility, operational complexity, and cost. These factors need to be considered when choosing imaging platform(s) for specific research purposes. Further technological developments are also needed to overcome some of the limitations, such as the short battery endurance in UAV operations and high cost of hyperspectral sensors.

Different analytical methods, such as linear regression, advanced regression, machine learning, deep learning, and RTM, have been explored in previous studies for analyzing the tremendous amount of information in hyperspectral images for investigating different agricultural features. Previous studies have mainly used the regression approach, while more physically based methods, such as RTM, have been less explored. Deep learning and effective big-data analytics are powerful tools for recognizing patterns in remote sensing data. Together with hyperspectral imagery, deep learning models have high potential to support the monitoring of a wide range of agricultural features. Different analytical methods have different advantages and disadvantages, and thus it is critical to compare these methods for specific research (e.g., requirements of accuracy and computing efficiency) and choose an optimal approach. In addition, image spectral information has been commonly used as variables for prediction or classification tasks, while other information, such as texture, has been less explored. Further, some other sources of data, such as weather, irrigation records, and historical yield information, can also be used in some of the analytical methods (e.g., machine learning and deep learning) for better monitoring of crop features. More research in these fields is also warranted.

Hyperspectral imaging has been successfully applied in a wide range of agricultural applications, including estimating crop biochemical and biophysical properties; evaluating crop nutrient and stress status; classifying or detecting crop types, weeds, and diseases; and investigating soil characteristics. Previous studies have focused on discussing one or two of the many factors impacting crop growth performance and productivity, and thus cannot evaluate crop status and growth-limiting factors comprehensively. It is important to integrate these factors to achieve a better understanding of their inter-relationships for optimal crop production and environmental protection. Besides, previous studies using hyperspectral imaging have mainly targeted investigating crop growth, aiming to improve crop yield, while less research has focused on understanding the ecosystem side of crop production (e.g., ecosystem services and biodiversity). Further research in these areas is warranted.

Author Contributions: Conceptualization, J.S., J.L., Y.H., B.L. and P.D.D.; methodology, B.L., P.D.D. and Y.H.; investigation, B.L.; writing —original draft preparation, B.L.; writing-review and editing, P.D.D., J.S., J.L. and Y.H.; project administration, J.S., J.L. and Y.H.; funding acquisition, Y.H. All authors have read and agreed to the published version of the manuscript.

Funding: This work was funded by the Natural Sciences and Engineering Research Council of Canada (NSERC) under Discovery Grant RGPIN-386183 to Professor Yuhong He.

Conflicts of Interest: The authors declare no conflict of interest.

\section{Abbreviations}

ALI

APEX

AVIS

AVIS

AVIRIS

ANN

CAI
Advanced Land Imager

Airborne Prism Experiment

Airborne Visible Near-Infrared Imaging Spectrometer

Airborne Visible Near-Infrared Imaging Spectrometer

Airborne Visible/Infrared Imaging Spectrometer

Artificial Neural Networks

Cellulose Absorption Index 


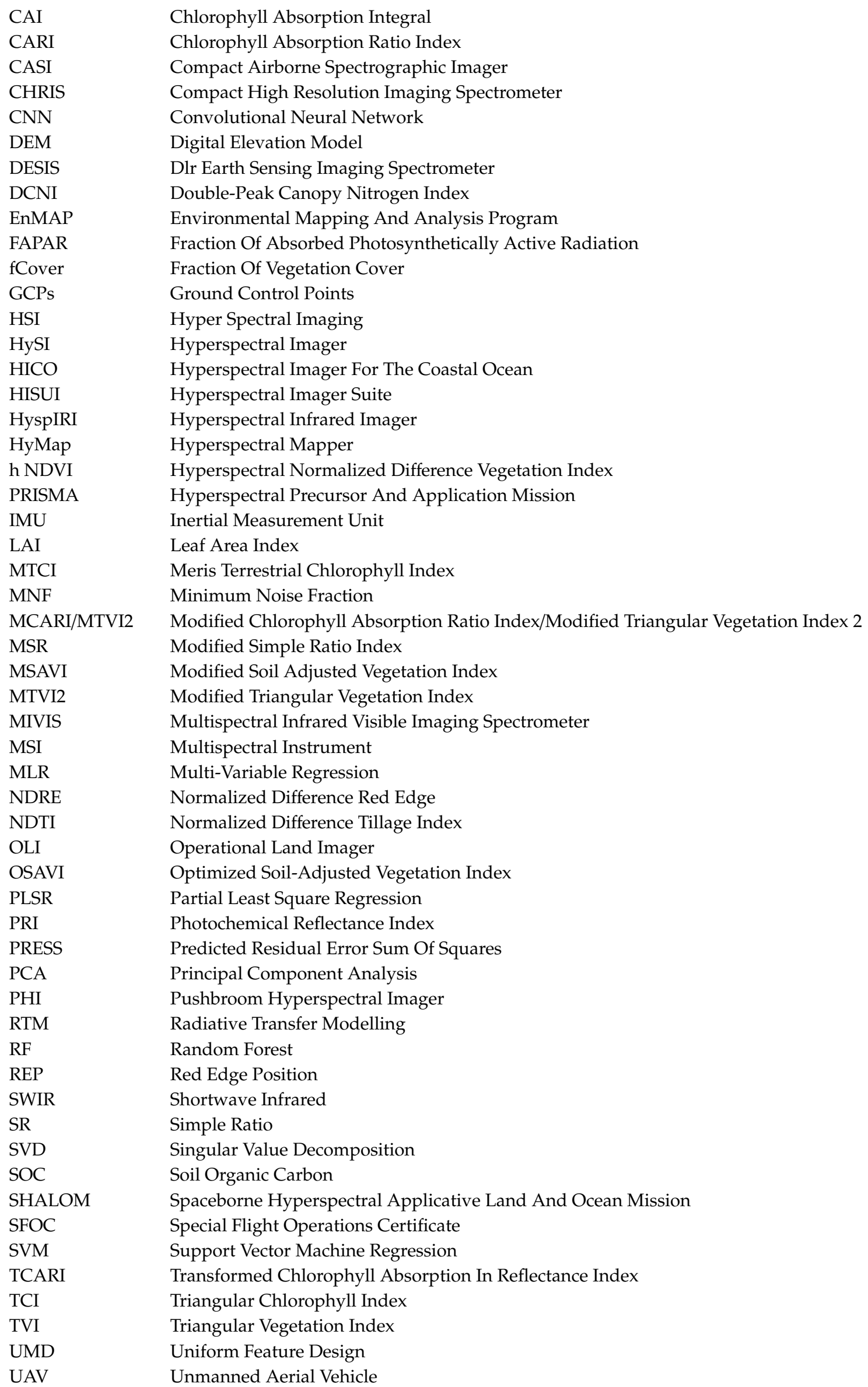




\section{References}

1. Weiss, M.; Jacob, F.; Duveiller, G. Remote sensing for agricultural applications: A meta-review. Remote Sens. Environ. 2020, 236, 111402. [CrossRef]

2. Liu, J.; Miller, J.R.; Haboudane, D.; Pattey, E.; Nolin, M.C. Variability of seasonal CASI image data products and potential application for management zone delineation for precision agriculture. Can. J. Remote Sens. 2005, 31, 400-411. [CrossRef]

3. Jensen, J.R. Remote Sensing of the Environment: An Earth Resource Perspective; Prentice Hall: Upper Saddle River, NJ, USA, 2006.

4. Sahoo, R.N.; Ray, S.S.; Manjunath, K.R. Hyperspectral remote sensing of agriculture. Curr. Sci. 2015, 108, 848-859.

5. Alonso, F.G.; Soria, S.L.; Gozalo, J.C. Comparing two methodologies for crop area estimation in Spain using Landsat TM images and ground-gathered data. Remote Sens. Environ. 1991, 35, 29-35. [CrossRef]

6. McNairn, H.; Champagne, C.; Shang, J.; Holmstrom, D.; Reichert, G. Integration of optical and Synthetic Aperture Radar (SAR) imagery for delivering operational annual crop inventories. ISPRS J. Photogramm. 2009, 64, 434-449. [CrossRef]

7. Shoshany, M.; Goldshleger, N.; Chudnovsky, A. Monitoring of agricultural soil degradation by remote-sensing methods: A review. Int. J. Remote Sens. 2013, 34, 6152-6181. [CrossRef]

8. Hunt, E.R.; Daughtry, C.S.T. What good are unmanned aircraft systems for agricultural remote sensing and precision agriculture? Int. J. Remote Sens. 2018, 39, 5345-5376. [CrossRef]

9. Thenkabail, P.S. Biophysical and yield information for precision farming from near-real-time and historical Landsat TM images. Int. J. Remote Sens. 2003, 24, 2879-2904. [CrossRef]

10. Shang, J.; Liu, J.; Ma, B.; Zhao, T.; Jiao, X.; Geng, X.; Huffman, T.; Kovacs, J.M.; Walters, D. Mapping spatial variability of crop growth conditions using RapidEye data in Northern Ontario, Canada. Remote Sens. Environ. 2015, 168, 113-125. [CrossRef]

11. Adão, T.; Hruška, J.; Pádua, L.; Bessa, J.; Peres, E.; Morais, R.; Sousa, J. Hyperspectral Imaging: A Review on UAV-Based Sensors, Data Processing and Applications for Agriculture and Forestry. Remote Sens. 2017, 9, 1110. [CrossRef]

12. Lucieer, A.; Malenovský, Z.; Veness, T.; Wallace, L. HyperUAS-imaging spectroscopy from a multirotor unmanned aircraft system. J. Field Robot. 2014, 31, 571-590. [CrossRef]

13. Gonzalez-Dugo, V.; Hernandez, P.; Solis, I.; Zarco-Tejada, P. Using High-Resolution Hyperspectral and Thermal Airborne Imagery to Assess Physiological Condition in the Context of Wheat Phenotyping. Remote Sens. 2015, 7, 13586-13605. [CrossRef]

14. Lee, K.; Cohen, W.B.; Kennedy, R.E.; Maiersperger, T.K.; Gower, S.T. Hyperspectral versus multispectral data for estimating leaf area index in four different biomes. Remote Sens. Environ. 2004, 91, 508-520. [CrossRef]

15. Mariotto, I.; Thenkabail, P.S.; Huete, A.; Slonecker, E.T.; Platonov, A. Hyperspectral versus multispectral crop-productivity modeling and type discrimination for the HyspIRI mission. Remote Sens. Environ. 2013, 139, 291-305. [CrossRef]

16. Marshall, M.; Thenkabail, P. Advantage of hyperspectral EO-1 Hyperion over multispectral IKONOS, GeoEye-1, WorldView-2, Landsat ETM+, and MODIS vegetation indices in crop biomass estimation. ISPRS J. Photogramm. 2015, 108, 205-218. [CrossRef]

17. Sun, J.; Yang, J.; Shi, S.; Chen, B.; Du, L.; Gong, W.; Song, S. Estimating Rice Leaf Nitrogen Concentration: Influence of Regression Algorithms Based on Passive and Active Leaf Reflectance. Remote Sens. 2017, 9, 951. [CrossRef]

18. Darvishzadeh, R.; Matkan, A.A.; Ahangar, A.D. Inversion of a radiative transfer model for estimation of rice canopy chlorophyll content using a lookup-table approach. IEEE J.-STARS 2012, 5, 1222-1230. [CrossRef]

19. Hruska, R.; Mitchell, J.; Anderson, M.; Glenn, N.F. Radiometric and geometric analysis of hyperspectral imagery acquired from an unmanned aerial vehicle. Remote Sens. 2012, 4, 2736-2752. [CrossRef]

20. Transon, J.; d'Andrimont, R.; Maugnard, A.; Defourny, P. Survey of Hyperspectral Earth Observation Applications from Space in the Sentinel-2 Context. Remote Sens. 2018, 10, 157. [CrossRef]

21. Lodhi, V.; Chakravarty, D.; Mitra, P. Hyperspectral Imaging System: Development Aspects and Recent Trends. Sens. Imaging 2019, 20, 1-24. [CrossRef] 
22. Hatfield, J.L.; Prueger, J.H. Value of Using Different Vegetative Indices to Quantify Agricultural Crop Characteristics at Different Growth Stages under Varying Management Practices. Remote Sens. 2010, 2, 562-578. [CrossRef]

23. Zhang, H.; Lan, Y.; Suh, C.P.C.; Westbrook, J.; Clint Hoffmann, W.; Yang, C.; Huang, Y. Fusion of remotely sensed data from airborne and ground-based sensors to enhance detection of cotton plants. Comput. Electron. Agric. 2013, 93, 55-59. [CrossRef]

24. Mahajan, G.R.; Pandey, R.N.; Sahoo, R.N.; Gupta, V.K.; Datta, S.C.; Kumar, D. Monitoring nitrogen, phosphorus and sulphur in hybrid rice (Oryza sativa L.) using hyperspectral remote sensing. Precis. Agric. 2017, 18, 736-761. [CrossRef]

25. Skauli, T.; Goa, P.E.; Baarstad, I.; Loke, T. A compact combined hyperspectral and polarimetric imager. In Proceedings of the Society of Photo-Optical Instrumentation Engineers, Stockholm, Sweden, 5 October 2006; Driggers, R.G., Huckridge, D.A., Eds.; SPIE-INT SOC Optical Engineering: Bellingham, WA, USA, 2016; Volume 6395, pp. 44-51.

26. Zarco-Tejada, P.J.; Suarez, L.; Gonzalez-Dugo, V. Spatial resolution effects on chlorophyll fluorescence retrieval in a heterogeneous canopy using hyperspectral imagery and radiative transfer simulation. IEEE Geosci. Remote Soc. 2013, 10, 937-941. [CrossRef]

27. Lu, B.; He, Y.; Dao, P.D. Comparing the Performance of Multispectral and Hyperspectral Images for Estimating Vegetation Properties. IEEE J. STARS 2019, 12, 1784-1797. [CrossRef]

28. ISS Utilization: MUSES-DESIS (Multi-User System for Earth Sensing) with DESIS instrument. Available online: https://directory.eoportal.org/web/eoportal/satellite-missions/content/-/article/iss-muses (accessed on 3 August 2020).

29. PRISMA (Hyperspectral Precursor and Application Mission). Available online: https://directory.eoportal. org/web/eoportal/satellite-missions/p/prisma-hyperspectral\#launch (accessed on 3 August 2020).

30. Satellite Missions Database. Available online: https:/directory.eoportal.org/web/eoportal/satellite-missions (accessed on 10 November 2019).

31. EnMAP (Environmental Monitoring and Analysis Program). Available online: https://directory.eoportal.org/ web/eoportal/satellite-missions/e/enmap (accessed on 3 August 2020).

32. Mitchell, J.J.; Glenn, N.F.; Anderson, M.O.; Hruska, R.C.; Halford, A.; Baun, C.; Nydegger, N. Unmanned Aerial Vehicle (UAV) hyperspectral remote sensing for dryland vegetation monitoring. In Proceedings of the 2012 4th Workshop on Hyperspectral Image and Signal Processing: Evolution in Remote Sensing (WHISPERS), Shanghai, China, 4-7 June 2012; pp. 1-10.

33. Zarco-Tejada, P.J.; Guillén-Climent, M.L.; Hernández-Clemente, R.; Catalina, A.; González, M.R.; Martín, P. Estimating leaf carotenoid content in vineyards using high resolution hyperspectral imagery acquired from an unmanned aerial vehicle (UAV). Agric. Forest Meteorol. 2013, 171, 281-294. [CrossRef]

34. Copenhaver, K.; Hellmich, R.; Hunt, T.; Glaser, J.; Sappington, T.; Calvin, D.; Carroll, M.; Fridgen, J. Use of spectral vegetation indices derived from airborne hyperspectral imagery for detection of European corn borer infestation in Iowa corn plots. J. Econ. Entomol. 2008, 101, 1614-1623.

35. Ryu, C.; Suguri, M.; Umeda, M. Multivariate analysis of nitrogen content for rice at the heading stage using reflectance of airborne hyperspectral remote sensing. Field Crops Res. 2011, 122, 214-224. [CrossRef]

36. Lu, B.; He, Y. Evaluating Empirical Regression, Machine Learning, and Radiative Transfer Modelling for Estimating Vegetation Chlorophyll Content Using Bi-Seasonal Hyperspectral Images. Remote Sens. 2019, 11, 1979. [CrossRef]

37. Yu, F.; Xu, T.; Du, W.; Ma, H.; Zhang, G.; Chen, C. Radiative transfer models (RTMs) for field phenotyping inversion of rice based on UAV hyperspectral remote sensing. Int. J. Agric. Biol. Eng. 2017, 10, 150-157.

38. Teke, M.; Deveci, H.S.; Haliloglu, O.; Gurbuz, S.Z.; Sakarya, U. A short survey of hyperspectral remote sensing applications in agriculture. In Proceedings of the 2013 6th International Conference on Recent Advances in Space Technologies (RAST), Istanbul, Turkey, 12-14 June 2013; IEEE: New York, NY, USA, 2013; pp. 171-176.

39. Dale, L.M.; Thewis, A.; Boudry, C.; Rotar, I.; Dardenne, P.; Baeten, V.; Pierna, J.A.F. Hyperspectral Imaging Applications in Agriculture and Agro-Food Product Quality and Safety Control: A Review. Appl. Spectrosc. Rev. 2013, 48, 142-159. [CrossRef]

40. Tiangong/Shenzhou: China's Human Spaceflight Program/Tianzhou Cargo Spaceship. Available online: https://directory.eoportal.org/web/eoportal/satellite-missions/t/tiangong (accessed on 3 August 2020). 
41. Apan, A.; Held, A.; Phinn, S.; Markley, J. Detecting sugarcane 'orange rust' disease using EO-1 Hyperion hyperspectral imagery. Int. J. Remote Sens. 2004, 25, 489-498. [CrossRef]

42. Dutta, S.; Bhattacharya, B.K.; Rajak, D.R.; Chattopadhayay, C.; Patel, N.K.; Parihar, J.S. Disease detection in mustard crop using eo-1 hyperion satellite data. J. Indian Soc. Remote 2006, 34, 325-330. [CrossRef]

43. Moharana, S.; Dutta, S. Spatial variability of chlorophyll and nitrogen content of rice from hyperspectral imagery. ISPRS J. Photogramm. 2016, 122, 17-29. [CrossRef]

44. Thenkabail, P.S.; Mariotto, I.; Gumma, M.K.; Middleton, E.M.; Landis, D.R.; Huemmrich, K.F. Selection of Hyperspectral Narrowbands (HNBs) and Composition of Hyperspectral Twoband Vegetation Indices (HVIs) for Biophysical Characterization and Discrimination of Crop Types Using Field Reflectance and Hyperion/EO-1 Data. IEEE J. STARS 2013, 6, 427-439. [CrossRef]

45. Wu, C.; Han, X.; Niu, Z.; Dong, J. An evaluation of EO-1 hyperspectral Hyperion data for chlorophyll content and leaf area index estimation. Int. J. Remote Sens. 2010, 31, 1079-1086. [CrossRef]

46. Bannari, A.; Staenz, K.; Champagne, C.; Khurshid, K. Spatial Variability Mapping of Crop Residue Using Hyperion (EO-1) Hyperspectral Data. Remote Sens. 2015, 7, 8107-8127. [CrossRef]

47. Galloza, M.S.; Crawford, M. Exploiting multisensor spectral data to improve crop residue cover estimates for management of agricultural water quality. In Proceedings of the IEEE Geoscience and Remote Sensing Society Symposium, Vancouver, BC, Canada, 24-29 July 2011; IEEE: New York, NY, USA, 2011; pp. 3668-3671.

48. Camacho Velasco, A.; Vargas García, C.A.; Arguello Fuentes, H. A comparative study of target detection algorithms in hyperspectral imagery applied to agricultural crops in Colombia. Revista Tecnura 2016, 20, 86-99. [CrossRef]

49. Gomez, C.; Rossel, R.A.V.; McBratney, A.B. Soil organic carbon prediction by hyperspectral remote sensing and field vis-NIR spectroscopy: An Australian case study. Geoderma 2008, 146, 403-411. [CrossRef]

50. Zhang, T.; Li, L.; Zheng, B. Estimation of agricultural soil properties with imaging and laboratory spectroscopy. J. Appl. Remote Sens. 2013, 7, 73587. [CrossRef]

51. Bostan, S.; Ortak, M.A.; Tuna, C.; Akoguz, A.; Sertel, E.; Ustundag, B.B. Comparison of classification accuracy of co-located hyperspectral \& multispectral images for agricultural purposes. In Proceedings of the 2016 Fifth International Conference on Agro-Geoinformatics (Agro-Geoinformatics), Tianjin, China, 18-20 July 2016; IEEE: New York, NY, USA, 2016; pp. 1-4.

52. Lodhi, V.; Chakravarty, D.; Mitra, P. Hyperspectral Imaging for Earth Observation: Platforms and Instruments. J. Indian Inst. Sci. 2018, 98, 429-443. [CrossRef]

53. Aasen, H.; Bolten, A. Multi-temporal high-resolution imaging spectroscopy with hyperspectral 2D imagers From theory to application. Remote Sens. Environ. 2018, 205, 374-389. [CrossRef]

54. Jia, X.; Li, S.; Ke, S.; Hu, B. Overview of spaceborne hyperspectral imagers and the research progress in bathymetric maps. In Proceedings of the Second Target Recognition and Artificial Intelligence Summit Forum. International Society for Optics and Photonics, Shenyang, China, 28-30 August 2019; SPIE-INT SOC Optical Engineering: Bellingham, WA, USA, 2020.

55. Headwall Hyperspectral Sensors. Available online: https://www.headwallphotonics.com/hyperspectralsensors (accessed on 8 May 2020).

56. Pullanagari, R.R.; Kereszturi, G.; Yule, I. Integrating Airborne Hyperspectral, Topographic, and Soil Data for Estimating Pasture Quality Using Recursive Feature Elimination with Random Forest Regression. Remote Sens. 2018, 10, 1117. [CrossRef]

57. Verger, A.; Baret, F.; Camacho, F. Optimal modalities for radiative transfer-neural network estimation of canopy biophysical characteristics: Evaluation over an agricultural area with CHRIS/PROBA observations. Remote Sens. Environ. 2011, 115, 415-426. [CrossRef]

58. Antony, R.; Ray, S.S.; Panigrahy, S. Discrimination of wheat crop stage using CHRIS/PROBA multi-angle narrowband data. Remote Sens. Lett. 2011, 2, 71-80. [CrossRef]

59. Casa, R.; Castaldi, F.; Pascucci, S.; Palombo, A.; Pignatti, S. A comparison of sensor resolution and calibration strategies for soil texture estimation from hyperspectral remote sensing. Geoderma 2013, 197, 17-26. [CrossRef]

60. Kumar, A.S.K.; Samudraiah, D.R.M. Hyperspectral Imager Onboard Indian Mini Satellite-1. In Optical Payloads for Space Missions; Qian, S., Ed.; John Wiley \& Sons: Hoboken, NJ, USA, 2015; Volume 6, pp. 141-160.

61. IMS-1 (Indian Microsatellite-1). Available online: https://directory.eoportal.org/web/eoportal/satellitemissions/i/ims-1 (accessed on 31 March 2020).

62. Raval, M.S. Hyperspectral Imaging: A Paradigm in Remote Sensing. CSI Commun. 2014, 7, 7-9. 
63. Khobragade, A.N.; Raghuwanshi, M.M. Contextual Soft Classification Approaches for Crops Identification Using Multi-sensory Remote Sensing Data: Machine Learning Perspective for Satellite Images. In Artificial Intelligence Perspectives and Applications; Springer: Cham, Switzerland, 2015; pp. 333-346.

64. Hyperspectral Imager for the Coastal Ocean. Available online: http://hico.coas.oregonstate.edu/ (accessed on 1 April 2020).

65. Krutz, D.; Müller, R.; Knodt, U.; Günther, B.; Walter, I.; Sebastian, I.; Säuberlich, T.; Reulke, R.; Carmona, E.; Eckardt, A.; et al. The Instrument Design of the DLR Earth SensingImaging Spectrometer (DESIS). Sensors 2019, 19, 1622. [CrossRef]

66. ISS Utilization: HISUI (Hyperspectral Imager Suite). Available online: https://eoportal.org/web/eoportal/ satellite-missions/content/-/article/iss-utilization-hisui-hyperspectral-imager-suite-\#launch (accessed on 1 April 2020).

67. Pignatti, S.; Palombo, A.; Pascucci, S.; Romano, F.; Santini, F.; Simoniello, T.; Umberto, A.; Vincenzo, C.; Acito, N.; Diani, M.; et al. The PRISMA hyperspectral mission: Science activities and opportunities for agriculture and land monitoring. In Proceedings of the 2013 IEEE International Geoscience and Remote Sensing Symposium-IGARSS, Melbourne, VIC, Australia, 21-26 July 2013; pp. 4558-4561.

68. EnMap Hyperspectral Imager. Available online: http://www.enmap.org/index.html (accessed on 1 December 2019).

69. Feingersh, T.; Ben-Dor, E. SHALOM-A Commercial Hyperspectral Space Mission. In Optical Payloads for Space Missions; Qian, S.E., Ed.; John Wiley \& Sons, Ltd.: Hoboken, NJ, USA, 2015; pp. 247-263.

70. Pandey, P.C.; Manevski, K.; Srivastava, P.K.; Petropoulos, G.P. The Use of Hyperspectral Earth Observation Data for Land Use/Cover Classification: Present Status, Challenges, and Future Outlook. In Hyperspectral Remote Sensing of Vegetation, 2nd ed.; Thenkabail, P.S., Lyon, J.G., Huete, A., Eds.; CRC Press: Boca Raton, FL, USA, 2018; Volume 4.

71. HyspIRI Mission Study. Available online: https://hyspiri.jpl.nasa.gov/ (accessed on 1 August 2020).

72. Malec, S.; Rogge, D.; Heiden, U.; Sanchez-Azofeifa, A.; Bachmann, M.; Wegmann, M. Capability of Spaceborne Hyperspectral EnMAP Mission for Mapping Fractional Cover for Soil Erosion Modeling. Remote Sens. 2015, 7, 11776-11800. [CrossRef]

73. Siegmann, B.; Jarmer, T.; Beyer, F.; Ehlers, M. The Potential of Pan-Sharpened EnMAP Data for the Assessment of Wheat LAI. Remote Sens. 2015, 7, 12737-12762. [CrossRef]

74. Locherer, M.; Hank, T.; Danner, M.; Mauser, W. Retrieval of Seasonal Leaf Area Index from Simulated EnMAP Data through Optimized LUT-Based Inversion of the PROSAIL Model. Remote Sens. 2015, 7, 10321-10346. [CrossRef]

75. Bachmann, M.; Makarau, A.; Segl, K.; Richter, R. Estimating the Influence of Spectral and Radiometric Calibration Uncertainties on EnMAP Data Products-Examples for Ground Reflectance Retrieval and Vegetation Indices. Remote Sens. 2015, 7, 10689-10714. [CrossRef]

76. Castaldi, F.; Palombo, A.; Santini, F.; Pascucci, S.; Pignatti, S.; Casa, R. Evaluation of the potential of the current and forthcoming multispectral and hyperspectral imagers to estimate soil texture and organic carbon. Remote Sens. Environ. 2016, 179, 54-65. [CrossRef]

77. Castaldi, F.; Palombo, A.; Pascucci, S.; Pignatti, S.; Santini, F.; Casa, R. Reducing the Influence of Soil Moisture on the Estimation of Clay from Hyperspectral Data: A Case Study Using Simulated PRISMA Data. Remote Sens. 2015, 7, 15561-15582. [CrossRef]

78. Ghasrodashti, E.; Karami, A.; Heylen, R.; Scheunders, P. Spatial Resolution Enhancement of Hyperspectral Images Using Spectral Unmixing and Bayesian Sparse Representation. Remote Sens. 2017, 9, 541. [CrossRef]

79. Yang, J.; Li, Y.; Chan, J.; Shen, Q. Image Fusion for Spatial Enhancement of Hyperspectral Image via Pixel Group Based Non-Local Sparse Representation. Remote Sens. 2017, 9, 53. [CrossRef]

80. Zhao, Y.; Yang, J.; Chan, J.C. Hyperspectral Imagery Super-Resolution by Spatial-Spectral Joint Nonlocal Similarity. IEEE J. STARS 2014, 7, 2671-2679. [CrossRef]

81. Loncan, L.; Almeida, L.B.; Bioucas-Dias, J.M.; Briottet, X.; Chanussot, J.; Dobigeon, N.; Fabre, S.; Liao, W.; Licciardi, G.A.; Simões, M.; et al. Hyperspectral pansharpening: A review. IEEE Geosci. Remote Sens. Mag. 2015, 3, 27-46. [CrossRef]

82. Asner, G.P.; Heidebrecht, K.B. Imaging spectroscopy for desertification studies: Comparing aviris and eo-1 hyperion in argentina drylands. IEEE Trans. Geosci. Remote 2003, 41, 1283-1296. [CrossRef] 
83. Weng, Y.; Gong, P.; Zhu, Z. A Spectral Index for Estimating Soil Salinity in the Yellow River Delta Region of China Using EO-1 Hyperion Data. Pedosphere 2010, 20, 378-388. [CrossRef]

84. Mulla, D.J. Twenty five years of remote sensing in precision agriculture: Key advances and remaining knowledge gaps. Biosyst. Eng. 2013, 114, 358-371. [CrossRef]

85. Jacquemoud, S.; Baret, F.; Andrieu, B.; Danson, F.M.; Jaggard, K. Extraction of vegetation biophysical parameters by inversion of the PROSPECT + SAIL models on sugar beet canopy reflectance data. Application to TM and AVIRIS sensors. Remote Sens. Environ. 1995, 52, 163-172. [CrossRef]

86. Gat, N.; Erives, H.; Fitzgerald, G.J.; Kaffka, S.R.; Maas, S.J. Estimating sugar beet yield using AVIRIS-derived indices. In Summaries of the 9th JPL Airborne Earth Science Workshop. Unpaginated CD; Jet Propulsion Laboratory: Pasadena, CA, USA, 2000.

87. Estep, L.; Terrie, G.; Davis, B. Crop stress detection using AVIRIS hyperspectral imagery and artificial neural networks. Int. J. Remote Sens. 2004, 25, 4999-5004. [CrossRef]

88. Cheng, Y.; Ustin, S.L.; Riano, D.; Vanderbilt, V.C. Water content estimation from hyperspectral images and MODIS indexes in Southeastern Arizona. Remote Sens. Environ. 2008, 112, 363-374. [CrossRef]

89. Palacios-Orueta, A.; Ustin, S.L. Remote Sensing of Soil Properties in the Santa Monica Mountains I. Spectral Analysis. Remote Sens. Environ. 1998, 65, 170-183. [CrossRef]

90. Gat, N.; Erives, H.; Maas, S.J.; Fitzgerald, G.J. Application of low altitude AVIRIS imagery of agricultural fields in the San Joaquin Valley, CA, to precision farming. In The 8th JPL Airborne Earth Science Workshop; Academia: Pasadena, CA, USA, 1999; pp. 145-150. Available online: https://www.researchgate.net/publication/2434575_Application_Of_Low_Altitude_Aviris_Imagery_ Of_Agricultural_Fields_In_The_San_Joaquin_Valley_Ca_To_Precision_Farming (accessed on 11 July 2020.).

91. Nigam, R.; Tripathy, R.; Dutta, S.; Bhagia, N.; Nagori, R.; Chandrasekar, K.; Kot, R.; Bhattacharya, B.K.; Ustin, S. Crop type discrimination and health assessment using hyperspectral imaging. Curr. Sci. 2019, 116, 1108-1123. [CrossRef]

92. Shivers, S.W.; Roberts, D.A.; McFadden, J.P. Using paired thermal and hyperspectral aerial imagery to quantify land surface temperature variability and assess crop stress within California orchards. Remote Sens. Environ. 2019, 222, 215-231. [CrossRef]

93. Ran, Q.; Li, W.; Du, Q.; Yang, C. Hyperspectral image classification for mapping agricultural tillage practices. J. Appl. Remote Sens. 2015, 9, 97298. [CrossRef]

94. Shivers, S.W.; Roberts, D.A.; McFadden, J.P.; Tague, C. Using Imaging Spectrometry to Study Changes in Crop Area in California's Central Valley during Drought. Remote Sens. 2018, 10, 1556. [CrossRef]

95. Haboudane, D.; Miller, J.R.; Tremblay, N.; Zarco-Tejada, P.J.; Dextraze, L. Integrated narrow-band vegetation indices for prediction of crop chlorophyll content for application to precision agriculture. Remote Sens. Environ. 2002, 81, 416-426. [CrossRef]

96. Liu, J.; Miller, J.R.; Haboudane, D.; Pattey, E.; Hochheim, K. Crop fraction estimation from casi hyperspectral data using linear spectral unmixing and vegetation indices. Can. J. Remote Sens. 2008, 34, S124-S138. [CrossRef]

97. Goel, P.K.; Prasher, S.O.; Landry, J.; Patel, R.M.; Viau, A.A. Hyperspectral image classification to detect weed infestations and nitrogen status in corn. Trans. ASAE 2003, 46, 539.

98. Richter, K.; Hank, T.; Mauser, W. Preparatory analyses and development of algorithms for agricultural applications in the context of the EnMAP hyperspectral mission. In Proceedings of the Remote Sensing for Agriculture, Ecosystems, and Hydrology XII. International Society for Optics and Photonics, Toulouse, France, 22 October 2010; pp. 782407-7824011.

99. Jarmer, T. Spectroscopy and hyperspectral imagery for monitoring summer barley. Int. J. Remote Sens. 2013, 34, 6067-6078. [CrossRef]

100. Thomas, U.; Philippe, D.; Christian, B.; Franz, R.; Frédéric, M.; Martin, S.; Miriam, M.; Lucien, H. Retrieving the Bioenergy Potential from Maize Crops Using Hyperspectral Remote Sensing. Remote Sens. 2013, 5, 254-273.

101. Mewes, T.; Franke, J.; Menz, G. Spectral requirements on airborne hyperspectral remote sensing data for wheat disease detection. Precis. Agric. 2011, 12, 795-812. [CrossRef]

102. Hbirkou, C.; Pätzold, S.; Mahlein, A.; Welp, G. Airborne hyperspectral imaging of spatial soil organic carbon heterogeneity at the field-scale. Geoderma 2012, 175-176, 21-28. [CrossRef] 
103. Cilia, C.; Panigada, C.; Rossini, M.; Meroni, M.; Busetto, L.; Amaducci, S.; Boschetti, M.; Picchi, V.; Colombo, R. Nitrogen Status Assessment for Variable Rate Fertilization in Maize through Hyperspectral Imagery. Remote Sens. 2014, 6, 6549-6565. [CrossRef]

104. Ambrus, A.; Burai, P.; Lénárt, C.; Enyedi, P.; Kovács, Z. Estimating biomass of winter wheat using narrowband vegetation indices for precision agriculture. J. Cent. Eur. Green Innov. 2015, 3, 13-22.

105. Oppelt, N.; Mauser, W. Hyperspectral monitoring of physiological parameters of wheat during a vegetation period using AVIS data. Int. J. Remote Sens. 2004, 25, 145-159. [CrossRef]

106. Bannari, A.; Pacheco, A.; Staenz, K.; McNairn, H.; Omari, K. Estimating and mapping crop residues cover on agricultural lands using hyperspectral and IKONOS data. Remote Sens. Environ. 2006, 104, 447-459. [CrossRef]

107. Van Wesemael, B.; Tychon, B.; Bartholomeus, H.; Kooistra, L.; van Leeuwen, M.; Stevens, A.; Ben-Dor, E. Soil Organic Carbon mapping of partially vegetated agricultural fields with imaging spectroscopy. Int. J. Appl. Earth Obs. 2011, 13, 81-88.

108. Finn, M.P.; Lewis, M.D.; Bosch, D.D.; Giraldo, M.; Yamamoto, K.; Sullivan, D.G.; Kincaid, R.; Luna, R.; Allam, G.K.; Kvien, C.; et al. Remote Sensing of Soil Moisture Using Airborne Hyperspectral Data. Gisci. Remote Sens. 2011, 48, 522-540. [CrossRef]

109. Xie, Q.; Huang, W.; Liang, D.; Chen, P.; Wu, C.; Yang, G.; Zhang, J.; Huang, L.; Zhang, D. Leaf Area Index Estimation Using Vegetation Indices Derived From Airborne Hyperspectral Images in Winter Wheat. IEEE J. STARS 2014, 7, 3586-3594. [CrossRef]

110. Castaldi, F.; Chabrillat, S.; Jones, A.; Vreys, K.; Bomans, B.; van Wesemael, B. Soil Organic Carbon Estimation in Croplands by Hyperspectral Remote APEX Data Using the LUCAS Topsoil Database. Remote Sens. 2018, 10, 153. [CrossRef]

111. Luo, S.; Wang, C.; Xi, X.; Zeng, H.; Li, D.; Xia, S.; Wang, P. Fusion of Airborne Discrete-Return LiDAR and Hyperspectral Data for Land Cover Classification. Remote Sens. 2016, 8, 3. [CrossRef]

112. Mart, L.; Tard, A.; Pal, V.; Arbiol, R. Atmospheric correction algorithm applied to CASI multi-height hyperspectral imagery. Parameters 2006, 1, 4.

113. AVIRIS Data-New Data Acquisitions. Available online: https://aviris.jpl.nasa.gov/data/newdata.html (accessed on 1 August 2020).

114. Lu, B.; He, Y. Species classification using Unmanned Aerial Vehicle (UAV)-acquired high spatial resolution imagery in a heterogeneous grassland. ISPRS J. Photogramm. 2017, 128, 73-85. [CrossRef]

115. Casa, R.; Pascucci, S.; Pignatti, S.; Palombo, A.; Nanni, U.; Harfouche, A.; Laura, L.; Di Rocco, M.; Fantozzi, P. UAV-based hyperspectral imaging for weed discrimination in maize. In Precision Agriculture '19; Stafford, J.V., Ed.; Wageningen Academic Publishers: Wageningen, The Netherlands, 2019; pp. 24-35.

116. Dao, P.D.; He, Y.; Lu, B. Maximizing the quantitative utility of airborne hyperspectral imagery for studying plant physiology: An optimal sensor exposure setting procedure and empirical line method for atmospheric correction. Int. J. Appl. Earth Obs. 2019, 77, 140-150. [CrossRef]

117. Capolupo, A.; Kooistra, L.; Berendonk, C.; Boccia, L.; Suomalainen, J. Estimating plant traits of grasslands from UAV-acquired hyperspectral images: A comparison of statistical approaches. ISPRS Int. J. Geo Inf. 2015, 4, 2792-2820. [CrossRef]

118. Lu, B.; He, Y. Optimal spatial resolution of Unmanned Aerial Vehicle (UAV)-acquired imagery for species classification in a heterogeneous grassland ecosystem. Gisci. Remote Sens. 2018, 55, 205-220. [CrossRef]

119. Bohnenkamp, D.; Behmann, J.; Mahlein, A. In-Field Detection of Yellow Rust in Wheat on the Ground Canopy and UAV Scale. Remote Sens. 2019, 11, 2495. [CrossRef]

120. Habib, A.; Han, Y.; Xiong, W.; He, F.; Zhang, Z.; Crawford, M. Automated Ortho-Rectification of UAV-Based Hyperspectral Data over an Agricultural Field Using Frame RGB Imagery. Remote Sens. 2016, 8, 796. [CrossRef]

121. Honkavaara, E.; Saari, H.; Kaivosoja, J.; Pölönen, I.; Hakala, T.; Litkey, P.; Mäkynen, J.; Pesonen, L. Processing and assessment of spectrometric, stereoscopic imagery collected using a lightweight UAV spectral camera for precision agriculture. Remote Sens. 2013, 5, 5006-5039. [CrossRef]

122. Saari, H.; Pellikka, I.; Pesonen, L.; Tuominen, S.; Heikkila, J.; Holmlund, C.; Makynen, J.; Ojala, K.; Antila, T. Unmanned Aerial Vehicle (UAV) operated spectral camera system for forest and agriculture applications. In Proceedings of the Remote Sensing for Agriculture, Ecosystems, and Hydrology XIII. International Society for Optics and Photonics, Prague, Czech Republic, 6 October 2011; Volume 8174. 
123. Honkavaara, E.; Kaivosoja, J.; Mäkynen, J.; Pellikka, I.; Pesonen, L.; Saari, H.; Salo, H.; Hakala, T.; Marklelin, L.; Rosnell, T. Hyperspectral reflectance signatures and point clouds for precision agriculture by light weight UAV imaging system. ISPRS Ann. Photogramm. Remote Sens. Spat. Inf. Sci. 2012, 7, 353-358. [CrossRef]

124. Yue, J.; Yang, G.; Li, C.; Li, Z.; Wang, Y.; Feng, H.; Xu, B. Estimation of Winter Wheat Above-Ground Biomass Using Unmanned Aerial Vehicle-Based Snapshot Hyperspectral Sensor and Crop Height Improved Models. Remote Sens. 2017, 9, 708. [CrossRef]

125. Pölönen, I.; Saari, H.; Kaivosoja, J.; Honkavaara, E.; Pesonen, L. Hyperspectral imaging based biomass and nitrogen content estimations from light-weight UAV. In Proceedings of the Remote Sensing for Agriculture, Ecosystems, and Hydrology XV. International Society for Optics and Photonics, Dresden, Germany, 16 October 2013; p. 88870J.

126. Kaivosoja, J.; Pesonen, L.; Kleemola, J.; Pölönen, I.; Salo, H.; Honkavaara, E.; Saari, H.; Mäkynen, J.; Rajala, A. A case study of a precision fertilizer application task generation for wheat based on classified hyperspectral data from UAV combined with farm history data. In Proceedings of the SPIE Remote Sensing, Dresden, Germany, 24-26 September 2013; pp. 1-11.

127. Akhtman, Y.; Golubeva, E.; Tutubalina, O.; Zimin, M. Application of hyperspectural images and ground data for precision farming. Geogr. Environ. Sustain. 2017, 10, 117-128. [CrossRef]

128. Izzo, R.R.; Lakso, A.N.; Marcellus, E.D.; Bauch, T.D.; Raqueno, N.G.; van Aardt, J. An initial analysis of real-time sUAS-based detection of grapevine water status in the Finger Lakes Wine Country of Upstate New York. In Proceedings of the Autonomous Air and Ground Sensing Systems for Agricultural Optimization and Phenotyping IV; International Society for Optics and Photonics: Baltimore, MD, USA, 2019.

129. Scherrer, B.; Sheppard, J.; Jha, P.; Shaw, J.A. Hyperspectral imaging and neural networks to classify herbicide-resistant weeds. J. Appl. Remote Sens. 2019, 13, 044516. [CrossRef]

130. Yue, J.; Feng, H.; Jin, X.; Yuan, H.; Li, Z.; Zhou, C.; Yang, G.; Tian, Q. A Comparison of Crop Parameters Estimation Using Images from UAV-Mounted Snapshot Hyperspectral Sensor and High-Definition Digital Camera. Remote Sens. 2018, 10, 1138. [CrossRef]

131. Dalponte, M.; Orka, H.O.; Gobakken, T.; Gianelle, D.; Naesset, E. Tree Species Classification in Boreal Forests with Hyperspectral Data. IEEE Trans. Geosci. Remote 2013, 51, 2632-2645. [CrossRef]

132. Aasen, H.; Bendig, J.; Bolten, A.; Bennertz, S.; Willkomm, M.; Bareth, G. Introduction and preliminary results of a calibration for full-frame hyperspectral cameras to monitor agricultural crops with UAVs. Int. Arch. Photogramm. Remote Sens. Spat. Inf. Sci. 2014, XL-7, 1-8. [CrossRef]

133. Zhu, W.; Sun, Z.; Huang, Y.; Lai, J.; Li, J.; Zhang, J.; Yang, B.; Li, B.; Li, S.; Zhu, K.; et al. Improving Field-Scale Wheat LAI Retrieval Based on UAV Remote-Sensing Observations and Optimized VI-LUTs. Remote Sens. 2019, 11, 2456. [CrossRef]

134. Zhao, J.; Zhong, Y.; Hu, X.; Wei, L.; Zhang, L. A robust spectral-spatial approach to identifying heterogeneous crops using remote sensing imagery with high spectral and spatial resolutions. Remote Sens. Environ. 2020, 239, 111605. [CrossRef]

135. Zarco-Tejada, P.J.; González-Dugo, V.; Berni, J.A.J. Fluorescence, temperature and narrow-band indices acquired from a UAV platform for water stress detection using a micro-hyperspectral imager and a thermal camera. Remote Sens. Environ. 2012, 117, 322-337. [CrossRef]

136. Lu, B.; He, Y.; Liu, H.H.T. Mapping vegetation biophysical and biochemical properties using unmanned aerial vehicles-acquired imagery. Int. J. Remote Sens. 2018, 39, 5265-5287. [CrossRef]

137. Malmir, M.; Tahmasbian, I.; Xu, Z.; Farrar, M.B.; Bai, S.H. Prediction of soil macro- and micro-elements in sieved and ground air-dried soils using laboratory-based hyperspectral imaging technique. Geoderma 2019, 340, 70-80. [CrossRef]

138. Van de Vijver, R.; Mertens, K.; Heungens, K.; Somers, B.; Nuyttens, D.; Borra-Serrano, I.; Lootens, P.; Roldan-Ruiz, I.; Vangeyte, J.; Saeys, W. In-field detection of Altemaria solani in potato crops using hyperspectral imaging. Comput. Electron. Agric. 2020, 168, 105106. [CrossRef]

139. Eddy, P.R.; Smith, A.M.; Hill, B.D.; Peddle, D.R.; Coburn, C.A.; Blackshaw, R.E. Hybrid segmentation Artificial Neural Network classification of high resolution hyperspectral imagery for Site-Specific Herbicide Management in agriculture. Photogramm. Eng. Remote Sens. 2008, 74, 1249-1257. [CrossRef]

140. Feng, H.; Chen, G.; Xiong, L.; Liu, Q.; Yang, W. Accurate Digitization of the Chlorophyll Distribution of Individual Rice Leaves Using Hyperspectral Imaging and an Integrated Image Analysis Pipeline. Front. Plant Sci. 2017, 8, 1238. [CrossRef] 
141. Asaari, M.S.M.; Mishra, P.; Mertens, S.; Dhondt, S.; Inzé, D.; Wuyts, N.; Scheunders, P. Close-range hyperspectral image analysis for the early detection of stress responses in individual plants in a high-throughput phenotyping platform. ISPRS J. Photogramm. 2018, 138, 121-138. [CrossRef]

142. Zhu, W.; Li, J.; Li, L.; Wang, A.; Wei, X.; Mao, H. Nondestructive diagnostics of soluble sugar, total nitrogen and their ratio of tomato leaves in greenhouse by polarized spectra-hyperspectra Introduction to the pls Package 1 data fusion. Int. J. Agric. Biol. Eng. 2020, 13, 189-197.

143. Morel, J.; Jay, S.; Féret, J.; Bakache, A.; Bendoula, R.; Carreel, F.; Gorretta, N. Exploring the potential of PROCOSINE and close-range hyperspectral imaging to study the effects of fungal diseases on leaf physiology. Sci. Rep. 2018, 8, 1-13. [CrossRef] [PubMed]

144. Nagasubramanian, K.; Jones, S.; Singh, A.K.; Sarkar, S.; Singh, A.; Ganapathysubramanian, B. Plant disease identification using explainable 3D deep learning on hyperspectral images. Plant Methods 2019, 15, 98. [CrossRef] [PubMed]

145. Lopatin, J.; Fassnacht, F.E.; Kattenborn, T.; Schmidtlein, S. Mapping plant species in mixed grassland communities using close range imaging spectroscopy. Remote Sens. Environ. 2017, 201, 12-23. [CrossRef]

146. Behmann, J.; Mahlein, A.; Paulus, S.; Dupuis, J.; Kuhlmann, H.; Oerke, E.; Plümer, L. Generation and application of hyperspectral 3D plant models: Methods and challenges. Mach. Vis. Appl. 2016, 27, 611-624. [CrossRef]

147. Antonucci, F.; Menesatti, P.; Holden, N.M.; Canali, E.; Giorgi, S.; Maienza, A.; Stazi, S.R. Hyperspectral Visible and Near-Infrared Determination of Copper Concentration in Agricultural Polluted Soils. Commun. Soil Sci. Plan. 2012, 43, 1401-1411. [CrossRef]

148. Wan, P.; Yang, G.; Xu, B.; Feng, H.; Yu, H. Geometric Correction Method of Rotary Scanning Hyperspectral Image in Agriculture Application. In Proceedings of the Conferences of the Photoelectronic Technology Committee of the Chinese Society of Astronautics, Beijing, China, 13-15 May 2014.

149. Yeh, Y.; Chung, W.; Liao, J.; Chung, C.; Kuo, Y.; Lin, T. Strawberry foliar anthracnose assessment by hyperspectral imaging. Comput. Electron. Agric. 2016, 122, 1-9. [CrossRef]

150. Liu, Y.; Wang, T.; Ma, L.; Wang, N. Spectral calibration of hyperspectral data observed from a hyperspectrometer loaded on an Unmanned Aerial Vehicle platform. IEEE J. Sel. Top. Appl. Earth Obs. Remote Sens. 2014, 7, 2630-2638.

151. Miglani, A.; Ray, S.S.; Pandey, R.; Parihar, J.S. Evaluation of EO-1 hyperion data for agricultural applications. J. Indian Soc. Remote 2008, 36, 255-266. [CrossRef]

152. Amato, U.; Antoniadis, A.; Carfora, M.F.; Colandrea, P.; Cuomo, V.; Franzese, M.; Pignatti, S.; Serio, C. Statistical Classification for Assessing PRISMA Hyperspectral Potential for Agricultural Land Use. IEEE J. STARS 2013, 6, 615-625. [CrossRef]

153. Thenkabail, P.S.; Gumma, M.K.; Teluguntla, P.; Mohammed, I.A. Hyperspectral remote sensing of vegetation and agricultural crops. Photogramm. Eng. Remote Sens. J. Am. Soc. Photogramm. 2014, 80, 697-709.

154. Wang, Y.; Yao, H.; Zhao, S. Auto-encoder based dimensionality reduction. Neurocomputing 2016, 184, $232-242$. [CrossRef]

155. Hsu, P.; Tseng, Y.; Gong, P. Dimension Reduction of Hyperspectral Images for Classification Applications. Geogr. Inf. Sci. 2002, 8, 1-8. [CrossRef]

156. Abdolmaleki, M.; Fathianpour, N.; Tabaei, M. Evaluating the performance of the wavelet transform in extracting spectral alteration features from hyperspectral images. Int. J. Remote Sens. 2018, 39, 6076-6094. [CrossRef]

157. Cao, X.; Yao, J.; Fu, X.; Bi, H.; Hong, D. An Enhanced 3-D Discrete Wavelet Transform for Hyperspectral Image Classification. IEEE Geosci. Remote Soc. 2020, 1-5. [CrossRef]

158. Prabhakar, T.V.N.; Geetha, P. Two-dimensional empirical wavelet transform based supervised hyperspectral image classification. ISPRS J. Photogramm. 2017, 133, 37-45. [CrossRef]

159. Geng, X.; Sun, K.; Ji, L.; Zhao, Y. A Fast Volume-Gradient-Based Band Selection Method for Hyperspectral Image. IEEE Trans. Geosci. Remote 2014, 52, 7111-7119. [CrossRef]

160. Wang, C.; Gong, M.; Zhang, M.; Chan, Y. Unsupervised Hyperspectral Image Band Selection via Column Subset Selection. IEEE Geosci. Remote Soc. 2015, 12, 1411-1415. [CrossRef]

161. Wang, Q.; Lin, J.; Yuan, Y. Salient Band Selection for Hyperspectral Image Classification via Manifold Ranking. IEEE Trans. Neural Netw. Learn. Syst. 2016, 27, 1279-1289. [CrossRef] 
162. Thenkabail, P.S.; Smith, R.B.; De Pauw, E. Hyperspectral vegetation indices and their relationships with agricultural crop characteristics. Remote Sens. Environ. 2000, 71, 158-182. [CrossRef]

163. Nevalainen, O.; Hakala, T.; Suomalainen, J.; Kaasalainen, S. Nitrogen concentration estimation with hyperspectral LiDAR. ISPRS Ann. Photogramm. Remote Sens. Spat. Inf. Sci. 2013, 2, 205-210. [CrossRef]

164. Huang, W.; Lamb, D.W.; Niu, Z.; Zhang, Y.; Liu, L.; Wang, J. Identification of yellow rust in wheat using in-situ spectral reflectance measurements and airborne hyperspectral imaging. Precis. Agric. 2007, 8, 187-197. [CrossRef]

165. Tong, A.; He, Y. Estimating and mapping chlorophyll content for a heterogeneous grassland: Comparing prediction power of a suite of vegetation indices across scales between years. ISPRS J. Photogramm. 2017, 126, 146-167. [CrossRef]

166. Haboudane, D.; Tremblay, N.; Miller, J.R.; Vigneault, P. Remote estimation of crop chlorophyll content using spectral indices derived from hyperspectral data. IEEE T. Geosci. Remote 2008, 46, 423-437. [CrossRef]

167. Main, R.; Cho, M.A.; Mathieu, R.; O’Kennedy, M.M.; Ramoelo, A.; Koch, S. An investigation into robust spectral indices for leaf chlorophyll estimation. ISPRS J. Photogramm. 2011, 66, 751-761. [CrossRef]

168. Peng, Y.; Gitelson, A.A. Remote estimation of gross primary productivity in soybean and maize based on total crop chlorophyll content. Remote Sens. Environ. 2012, 117, 440-448. [CrossRef]

169. Croft, H.; Chen, J.M.; Zhang, Y. The applicability of empirical vegetation indices for determining leaf chlorophyll content over different leaf and canopy structures. Ecol. Complex. 2014, 17, 119-130. [CrossRef]

170. Zhou, X.; Huang, W.; Kong, W.; Ye, H.; Luo, J.; Chen, P. Remote estimation of canopy nitrogen content in winter wheat using airborne hyperspectral reflectance measurements. Adv. Space Res. 2016, 58, 1627-1637. [CrossRef]

171. Yue, J.; Feng, H.; Yang, G.; Li, Z. A comparison of regression techniques for estimation of above-ground winter wheat biomass using near-surface spectroscopy. Remote Sens. 2018, 10, 66. [CrossRef]

172. Hansen, P.M.; Schjoerring, J.K. Reflectance measurement of canopy biomass and nitrogen status in wheat crops using normalized difference vegetation indices and partial least squares regression. Remote Sens. Environ. 2003, 86, 542-553. [CrossRef]

173. Nguyen, H.T.; Lee, B. Assessment of rice leaf growth and nitrogen status by hyperspectral canopy reflectance and partial least square regression. Eur. J. Agron. 2006, 24, 349-356. [CrossRef]

174. Pedregosa, F.; Varoquaux, G.; Gramfort, A.; Michel, V.; Thirion, B.; Grisel, O.; Blondel, M.; Prettenhofer, P.; Weiss, R.; Dubourg, V.; et al. Scikit-learn: Machine learning in Python. Mach. Learn. 2011, 12, 2825-2830.

175. Mevik, B.; Wehrens, R. Introduction to the PLS Package. Help Sect. "Pls" Package R Studio Softw; R Found. Stat. Comput.: Vienna, Austria, 2015; pp. 1-23.

176. Asner, G.P.; Martin, R.E.; Anderson, C.B.; Knapp, D.E. Quantifying forest canopy traits: Imaging spectroscopy versus field survey. Remote Sens. Environ. 2015, 158, 15-27. [CrossRef]

177. Kiala, Z.; Odindi, J.; Mutanga, O. Potential of interval partial least square regression in estimating leaf area index. S. Afr. J. Sci. 2017, 113, 40-48. [CrossRef]

178. Wang, Z.; Kawamura, K.; Sakuno, Y.; Fan, X.; Gong, Z.; Lim, J. Retrieval of Chlorophyll-a and Total Suspended Solids Using Iterative Stepwise Elimination Partial Least Squares (ISE-PLS) Regression Based on Field Hyperspectral Measurements in Irrigation Ponds in Higashihiroshima, Japan. Remote Sens. 2017, 9, 264. [CrossRef]

179. Mehmood, T.; Ahmed, B. The diversity in the applications of partial least squares: An overview. J. Chemometr. 2016, 30, 4-17. [CrossRef]

180. Jacquemoud, S.; Baret, F. PROSPECT-A model of leaf optical-properties spectra. Remote Sens. Environ. 1990, 34, 75-91. [CrossRef]

181. Jacquemoud, S.; Bacour, C.; Poilve, H.; Frangi, J.P. Comparison of four radiative transfer models to simulate plant canopies reflectance: Direct and inverse mode. Remote Sens. Environ. 2000, 74, 471-481. [CrossRef]

182. Casa, R.; Jones, H.G. Retrieval of crop canopy properties: A comparison between model inversion from hyperspectral data and image classification. Int. J. Remote Sens. 2004, 25, 1119-1130. [CrossRef]

183. Richter, K.; Hank, T.; Atzberger, C.; Locherer, M.; Mauser, W. Regularization strategies for agricultural monitoring: The EnMAP vegetation analyzer (AVA). In Proceedings of the 2012 IEEE International Geoscience and Remote Sensing Symposium, Munich, Germany, 22-27 July 2012; pp. 6613-6616.

184. Wu, C.; Wang, L.; Niu, Z.; Gao, S.; Wu, M. Nondestructive estimation of canopy chlorophyll content using Hyperion and Landsat/TM images. Int. J. Remote Sens. 2010, 31, 2159-2167. [CrossRef] 
185. Darvishzadeh, R.; Atzberger, C.; Skidmore, A.; Schlerf, M. Mapping grassland leaf area index with airborne hyperspectral imagery: A comparison study of statistical approaches and inversion of radiative transfer models. ISPRS J. Photogramm. 2011, 66, 894-906. [CrossRef]

186. Breiman, L. Random forests. Mach. Learn. 2001, 45, 5-32. [CrossRef]

187. Were, K.; Bui, D.T.; Dick, O.B.; Singh, B.R. A comparative assessment of support vector regression, artificial neural networks, and random forests for predicting and mapping soil organic carbon stocks across an Afromontane landscape. Ecol. Indic. 2015, 52, 394-403. [CrossRef]

188. Gao, J.; Nuyttens, D.; Lootens, P.; He, Y.; Pieters, J.G. Recognising weeds in a maize crop using a random forest machine-learning algorithm and near-infrared snapshot mosaic hyperspectral imagery. Biosyst. Eng. 2018, 170, 39-50. [CrossRef]

189. Siegmann, B.; Jarmer, T. Comparison of different regression models and validation techniques for the assessment of wheat leaf area index from hyperspectral data. Int. J. Remote Sens. 2015, 36, 4519-4534. [CrossRef]

190. Adam, E.; Deng, H.; Odindi, J.; Abdel-Rahman, E.M.; Mutanga, O. Detecting the Early Stage of Phaeosphaeria Leaf Spot Infestations in Maize Crop Using In Situ Hyperspectral Data and Guided Regularized Random Forest Algorithm. J. Spectrosc. 2017, 2017, 1-8. [CrossRef]

191. Kamilaris, A.; Prenafeta-Boldú, F.X. Deep learning in agriculture: A survey. Comput. Electron. Agric. 2018, 147, 70-90. [CrossRef]

192. Yuan, Q.; Shen, H.; Li, T.; Li, Z.; Li, S.; Jiang, Y.; Xu, H.; Tan, W.; Yang, Q.; Wang, J.; et al. Deep learning in environmental remote sensing: Achievements and challenges. Remote Sens. Environ. 2020, 241, 111716. [CrossRef]

193. Sharma, A.; Liu, X.; Yang, X. Land cover classification from multi-temporal, multi-spectral remotely sensed imagery using patch-based recurrent neural networks. Neural Netw. 2018, 105, 346-355. [CrossRef]

194. Zhang, C.; Sargent, I.; Pan, X.; Li, H.; Gardiner, A.; Hare, J.; Atkinson, P.M. Joint Deep Learning for land cover and land use classification. Remote Sens. Environ. 2019, 221, 173-187. [CrossRef]

195. Rezaee, M.; Mahdianpari, M.; Zhang, Y.; Salehi, B. Deep Convolutional Neural Network for Complex Wetland Classification Using Optical Remote Sensing Imagery. IEEE J. STARS 2018, 11, 3030-3039. [CrossRef]

196. Xu, Y.; Wu, L.; Xie, Z.; Chen, Z. Building Extraction in Very High Resolution Remote Sensing Imagery Using Deep Learning and Guided Filters. Remote Sens. 2018, 10, 144. [CrossRef]

197. Kuwata, K.; Shibasaki, R. Estimating crop yields with deep learning and remotely sensed data. In Proceedings of the 2015 IEEE International Geoscience and Remote Sensing Symposium (IGARSS), Milan, Italy, 26-31 July 2015; pp. 858-861.

198. Mohanty, S.P.; Hughes, D.P.; Salathé, M. Using Deep Learning for Image-Based Plant Disease Detection. Front. Plant Sci. 2016, 7, 1419. [CrossRef] [PubMed]

199. Ji, S.; Zhang, C.; Xu, A.; Shi, Y.; Duan, Y. 3D Convolutional Neural Networks for Crop Classification with Multi-Temporal Remote Sensing Images. Remote Sens. 2018, 10, 75. [CrossRef]

200. Ndikumana, E.; Ho Tong Minh, D.; Baghdadi, N.; Courault, D.; Hossard, L. Deep Recurrent Neural Network for Agricultural Classification using multitemporal SAR Sentinel-1 for Camargue, France. Remote Sens. 2018, 10, 1217. [CrossRef]

201. Singh, A.K.; Ganapathysubramanian, B.; Sarkar, S.; Singh, A. Deep Learning for Plant Stress Phenotyping: Trends and Future Perspectives. Trends Plant Sci. 2018, 23, 883-898. [CrossRef]

202. Chlingaryan, A.; Sukkarieh, S.; Whelan, B. Machine learning approaches for crop yield prediction and nitrogen status estimation in precision agriculture: A review. Comput. Electron. Agric. 2018, 151, 61-69. [CrossRef]

203. Song, X.; Zhang, G.; Liu, F.; Li, D.; Zhao, Y.; Yang, J. Modeling spatio-temporal distribution of soil moisture by deep learning-based cellular automata model. J. Arid Land 2016, 8, 734-748. [CrossRef]

204. Moharana, S.; Dutta, S. Estimation of water stress variability for a rice agriculture system from space-borne hyperion imagery. Agr. Water Manag. 2019, 213, 260-269. [CrossRef]

205. Yang, C. Airborne Hyperspectral Imagery for Mapping Crop Yield Variability. Geogr. Compass 2009, 3 , 1717-1731. [CrossRef]

206. Zimdahl, R.L. Six Chemicals That Changed Agriculture; Academic Press: Cambridge, MA, USA, 2015. 
207. Goel, P.K.; Prasher, S.O.; Landry, J.A.; Patel, R.M.; Bonnell, R.B.; Viau, A.A.; Miller, J.R. Potential of airborne hyperspectral remote sensing to detect nitrogen deficiency and weed infestation in corn. Comput. Electron. Agric. 2003, 38, 99-124. [CrossRef]

208. Quemada, M.; Gabriel, J.; Zarco-Tejada, P. Airborne Hyperspectral Images and Ground-Level Optical Sensors As Assessment Tools for Maize Nitrogen Fertilization. Remote Sens. 2014, 6, 2940-2962. [CrossRef]

209. Koppe, W.; Laudien, R.; Gnyp, M.L.; Jia, L.; Li, F.; Chen, X.; Bareth, G. Deriving winter wheat characteristics from combined radar and hyperspectral data analysis. In Proceedings of the Geoinformatics, Wuhan, China, 28-29 October 2006; Remotely Sensed Data and Information. SPIE-INT SOC Optical Engineering: Bellingham, WA, USA, 2006.

210. Castaldi, F.; Castrignano, A.; Casa, R. A data fusion and spatial data analysis approach for the estimation of wheat grain nitrogen uptake from satellite data. Int. J. Remote Sens. 2016, 37, 4317-4336. [CrossRef]

211. Zheng, H.; Zhou, X.; Cheng, T.; Yao, X.; Tian, Y.; Cao, W.; Zhu, Y. Evaluation of a uav-based hyperspectral frame camera for monitoring the leaf nitrogen concentration in rice. In Proceedings of the IEEE International Symposium on Geoscience and Remote Sensing IGARSS, Beijing, China, 10-15 July 2016; pp. 7350-7353.

212. Zhou, K.; Cheng, T.; Zhu, Y.; Cao, W.; Ustin, S.L.; Zheng, H.; Yao, X.; Tian, Y. Assessing the Impact of Spatial Resolution on the Estimation of Leaf Nitrogen Concentration Over the Full Season of Paddy Rice Using Near-Surface Imaging Spectroscopy Data. Front. Plant Sci. 2018, 9, 964. [CrossRef] [PubMed]

213. Nasi, R.; Viljanen, N.; Kaivosoja, J.; Alhonoja, K.; Hakala, T.; Markelin, L.; Honkavaara, E. Estimating Biomass and Nitrogen Amount of Barley and Grass Using UAV and Aircraft Based Spectral and Photogrammetric 3D Features. Remote Sens. 2018, 10, 1082. [CrossRef]

214. Nigon, T.J.; Mulla, D.J.; Rosen, C.J.; Cohen, Y.; Alchanatis, V.; Knight, J.; Rud, R. Hyperspectral aerial imagery for detecting nitrogen stress in two potato cultivars. Comput. Electron. Agric. 2015, 112, 36-46. [CrossRef]

215. Chen, S.; Chen, C.; Wang, C.; Yang, I.; Hsiao, S. Evaluation of nitrogen content in cabbage seedlings using hyper-spectral images. In Proceedings of the Optics East, Boston, MA, USA, 9-12 September 2007; p. L7610.

216. Miphokasap, P.; Wannasiri, W. Estimations of Nitrogen Concentration in Sugarcane Using Hyperspectral Imagery. Sustainability 2018, 10, 1266. [CrossRef]

217. Malmir, M.; Tahmasbian, I.; Xu, Z.; Farrar, M.B.; Bai, S.H. Prediction of macronutrients in plant leaves using chemometric analysis and wavelength selection. J. Soil. Sediment. 2020, 20, 249-259. [CrossRef]

218. Lowe, A.; Harrison, N.; French, A.P. Hyperspectral image analysis techniques for the detection and classification of the early onset of plant disease and stress. Plant Methods 2017, 13, 80. [CrossRef]

219. Kingra, P.K.; Majumder, D.; Singh, S.P. Application of Remote Sensing and Gis in Agriculture and Natural Resource Management Under Changing Climatic Conditions. Agric. Res. J. 2016, 53, 295. [CrossRef]

220. Karimi, Y.; Prasher, S.O.; McNairn, H.; Bonnell, R.B.; Dutilleul, P.; Goel, R.K. Classification accuracy of discriminant analysis, artificial neural networks, and decision trees for weed and nitrogen stress detection in corn. Trans. ASAE 2005, 48, 1261-1268. [CrossRef]

221. Zhang, Y.; Slaughter, D.C.; Staab, E.S. Robust hyperspectral vision-based classification for multi-season weed mapping. ISPRS J. Photogramm. 2012, 69, 65-73. [CrossRef]

222. Eddy, P.R.; Smith, A.M.; Hill, B.D.; Peddle, D.R.; Coburn, C.A.; Blackshaw, R.E. Weed and crop discrimination using hyperspectral image data and reduced bandsets. Can. J. Remote Sens. 2014, 39, 481-490. [CrossRef]

223. Liu, B.; Li, R.; Li, H.; You, G.; Yan, S.; Tong, Q. Crop/Weed Discrimination Using a Field Imaging Spectrometer System. Sensors 2019, 19, 5154. [CrossRef] [PubMed]

224. LÓPEZ-Granados, F. Weed detection for site-specific weed management: Mapping and real-time approaches. Weed Res. 2011, 51, 1-11. [CrossRef]

225. Thomas, S.; Kuska, M.T.; Bohnenkamp, D.; Brugger, A.; Alisaac, E.; Wahabzada, M.; Behmann, J.; Mahlein, A. Benefits of hyperspectral imaging for plant disease detection and plant protection: A technical perspective. J. Plant Dis. Protect. 2018, 125, 5-20. [CrossRef]

226. Bauriegel, E.; Giebel, A.; Geyer, M.; Schmidt, U.; Herppich, W.B. Early detection of Fusarium infection in wheat using hyper-spectral imaging. Comput. Electron. Agric. 2011, 75, 304-312. [CrossRef]

227. Zhang, N.; Pan, Y.; Feng, H.; Zhao, X.; Yang, X.; Ding, C.; Yang, G. Development of Fusarium head blight classification index using hyperspectral microscopy images of winter wheat spikelets. Biosyst. Eng. 2019, 186, 83-99. [CrossRef]

228. Mahlein, A.; Oerke, E.; Steiner, U.; Dehne, H. Recent advances in sensing plant diseases for precision crop protection. Eur. J. Plant Pathol. 2012, 133, 197-209. [CrossRef] 
229. Casa, R.; Castaldi, F.; Pascucci, S.; Basso, B.; Pignatti, S. Geophysical and Hyperspectral Data Fusion Techniques for In-Field Estimation of Soil Properties. Vadose Zone J. 2013, 12, vzj2012.0201. [CrossRef]

230. Casa, R.; Castaldi, F.; Pascucci, S.; Pignatti, S. Potential of hyperspectral remote sensing for field scale soil mapping and precision agriculture applications. Ital. J. Agron. 2012, 7, 43. [CrossRef]

231. Gedminas, L.; Martin, S. Soil Organic Matter Mapping Using Hyperspectral Imagery and Elevation Data. In IEEE Aerospace Conference Proceedings; IEEE: Big Sky, MT, USA, 2019.

232. Song, X.; Yan, G.; Wan, J.; Liu, L.; Xue, X.; Li, C.; Huang, W. Use of airborne hyperspectral imagery to investigate the influence of soil nitrogen supplies and variable-rate fertilization to winter wheat growth. In Proceedings of the SPIE, Florence, Italy, 11 October 2007.

233. Wang, W.; Li, Z.; Wang, C.; Zheng, D.; Du, H. Prediction of Available Potassium Content in Cinnamon Soil Using Hyperspectral Imaging Technology. Spectrosc. Spect. Anal. 2019, 39, 1579-1585.

234. McCann, C.; Repasky, K.S.; Lawrence, R.; Powell, S. Multi-temporal mesoscale hyperspectral data of mixed agricultural and grassland regions for anomaly detection. ISPRS J. Photogramm. 2017, 131, 121-133. [CrossRef]

(C) 2020 by the authors. Licensee MDPI, Basel, Switzerland. This article is an open access article distributed under the terms and conditions of the Creative Commons Attribution (CC BY) license (http://creativecommons.org/licenses/by/4.0/). 